\title{
IGLESIA Y ESTADO EN EL SIGLO XIX FRANCÉS: TOCQUEVILLE Y LA LIBERTAD DE ENSEÑANZA*
}

\section{CHURCH AND STATE IN XIX ${ }^{\text {th }}$ CENTURY FRANCE: TOCQUEVILLE AND FREEDOM OF EDUCATION}

\author{
Rafael D. García Pérez \\ ICS/Universidad de Navarra
}

SUMARIO: I. PREPARACIÓN DEL DEBATE: LAS TESIS CATÓLICAS. II. LA DISCUSIÓN DE L'ADRESSE DE 17 DE ENERO DE 1844. III. 3. EL SEGUNDO PROYECTO DE LEY VILLEMAIN. IV. LA DEFENSA DE LA LIBERTAD DE ENSEÑANZA EN LE COMMERCE. V. A MODO DE CONCLUSIÓN

\begin{abstract}
Resumen: La discusión en 1844 de un proyecto de ley sobre instrucción secundaria dio lugar a un amplio debate en Francia sobre el contenido y alcance de la libertad de educación consagrada en la Constitución de 1830. Frente a las posiciones extremas que defendian el monopolio de la Universidad o su liberalización absoluta, destaca la postura de Tocqueville favorable a una libertad regulada. Sin embargo, más allá del debate concreto de la ley, lo que se hallaba en juego era el lugar reservado a la Iglesia en el nuevo orden constitucional implantado por la monarquía de Julio.
\end{abstract}

Abstract: The discussion in 1844 of a draft law on secondary education gave rise to a broad debate in France about the content and scope of the freedom of education ordained by the Constitution of 1830. In opposition to those that defended the monopoly of the University or its absolute liberalization, Tocqueville was in favor of a regulated freedom. However, beyond the concrete debate of the law, what was at stake was the place reserved for the Church in the new constitutional order implemented by the July Monarchy.

Palabras clave: libertad de educación, Iglesia, Estado, Universidad, religión, liberalismo.

Key words: Freedom of Education, Church, State, University, Religion, Liberalism.

A lo largo del siglo XIX, la organización de la enseñanza en sus diferentes niveles, especialmente en el secundario y superior, constituyó un lugar privilegiado de discusión de problemas de más hondo calado, como el lugar de la Iglesia en el nuevo orden liberal y su relación con el Estado. La cuestión que latía en el fondo de los debates que de manera intermitente, pero con gran intensidad, se sucedieron a lo largo del siglo XIX era el papel del Estado y de la Iglesia en la

Este artículo ha sido realizado en el marco del proyecto DER2016-76619-P "Narrativas en conflicto: libertad religiosa y relaciones Iglesia-Estado en los siglos XIX y XX", financiado por el Ministerio de Economía y Competitividad. 
formación de los jóvenes y, por tanto, en el destino de la nueva sociedad francesa. Para liberales y doctrinarios resultaba clara la misión del Estado en la conformación de la nación francesa y en la formación de sus ciudadanos. Como diría Guizot en el debate sobre la libertad de enseñanza en 1844, correspondía a la Universidad el "gobierno de los espíritus". Resultaba preciso para la formación de los jóvenes el trabajo de una corporación laica, la Universidad, que en contacto con la sociedad y dependiendo del Estado imprimiese en los espíritus la dirección adecuada ${ }^{1}$. Se buscaba así la constitución de un verdadero poder espiritual $^{2}$. Sin embargo, como el propio Guizot reconocía, un sector de los católicos, minoritario desde su punto de vista, se oponía a ello por entender que la enseñanza filosófica que se impartía en la Universidad era contraria a la fe católica, o bien porque actuaban movidos por intereses politicos contrarios a la nueva sociedad ${ }^{3}$. A estos habia que sumar, además de los católicos liberales, aquellos otros que reivindicaban para la Iglesia el lugar que durante siglos le habia correspondido en la enseñanza y educación de la juventud francesa como parte de su misión evangelizadora.

En este trabajo nos proponemos analizar la postura de Tocqueville en el debate sobre la libertad de enseñanza al hilo de la discusión del proyecto de ley que en 1844 el ministro de Instrucción Pública Villemain presentó en las Cámaras legislativas. La historiografia ha destacado como regla general la moderación de las tesis defendidas en este ámbito por Tocqueville, es decir, su capacidad de situarse en el centro del espectro político ${ }^{4}$. Este es el resultado en algunos casos de adoptar como perspectiva la visión que Tocqueville ofrece de sí mismo, alejada tanto de los defensores del monopolio universitario como de aquellos que pretendian una libertad de enseñanza absoluta para el clero. Sin embargo, el debate sobre la libertad de educación puede ser abordado desde otras

1 "La grande difficulté de notre temps, tout le monde le reconnaît, c'est la direction, le gouvernement des esprits. Quand je dis le gouvernement des esprits, je n'entends rien que de conforme aux libertés dont nous jouissons maintenant. Mais en fin, au sein même de la liberté, les esprits ont besoin d'être dirigés, dressés; et vous le savez bien, et le clergé lui-même le sait bien, ce grand corps spirituel ne peut suffire aujourd'hui à une telle destination. L'Etat a évidemment besoin qu'un grand corps laïque, qu'une grande association profondément unie à la société, la connaissant bien, vivant dans son sein, unie aussi à l'Etat, tenant de l'Etat son pouvoir, sa direction, qu'une telle corporation exerce sur la jeunesse cette influence morale qui la forme à l'ordre, à la règle, et sans laquelle, quand une fois ils sont arrivés à l'âge mûr, les esprits s'échappent et se déchainent en tous sens". Sesión del 25 de abril de 1844. Recueil de la discussion de la loi sur l'instruction secondaire a la chambre des pairs, et des anciens projets de loi et autres documents sur cette matière, Paris, Librairie Administrative de Paul Dupont, 1844, p. 263.

2 Pierre Rosanvallon, Le moment Guizot, Gallimard, París, 1985, p. 234.

3 Recueil de la discussion, pp. 260-262.

4 Anna Maria Battista, Lo spirito liberale e lo spirito religioso. Tocqueville nel dibattito sulla scuola, Jaca book, Milán, 1975, pp. 22-23; Agnès Antoine, L'impensé de la démocratie. Tocqueville, la citoyenneté et la religion, Fayard, 2003, p. 210; Sonia Chabot, Éducation civique, instruction publique et liberté de l'enseignement dans l'oeuvre d'Alexis de Tocqueville, en Laurence Guellec, Tocqueville et l'esprit de la démocracie, Sciences Po, París, 2005, p. 258; Jean-Louis Benoît, Tocqueville, un destin paradoxal, Bayard cop., París, 2005, p. 248; David A. Selby, Tocqueville, Jansenism and the Necessity of the Political in a Democratic Age. Building a Republic for the Moderns, Amsterdam University Press, Amsterdam, 2015, p. 167; Alan S. Kahan, Tocqueville, Democracy and Religion: Checks and Balances for Democratic Souls, Oxford University Press, Oxford, 2015, p. 158. 
perspectivas en las cuales el centro y los extremos revisten significados diversos. Así, cuando se trata de la defensa de derechos fundamentales, el término medio no es siempre el más razonable.

La postura de Tocqueville respondió en buena medida al deseo de evitar un conflicto frontal entre el clero y la sociedad nueva, siempre con el objetivo de impedir que la religión perdiera influencia social con las consecuencias negativas para la libertad que de ello podian derivarse. Esta posición "intermedia" se tradujo en la adopción de unas tesis que dejaban amplio espacio de actuación al Estado en el control de la educación y de las congregaciones religiosas, al tiempo que rompian el monopolio ejercido, al menos de iure, por la Universidad hasta ese momento. En este sentido, Tocqueville se pronunció claramente a favor de la libertad de enseñanza alineándose en muchos de sus postulados con la posición católica. En este conflicto sobre la educación los católicos se situaron, en efecto, en el bando de la libertad, rompiendo el relato ilustrado-liberal que desde el siglo XVIII situaba necesariamente al bando católico en el partido de la intolerancia y el fanatismo. En este sentido, Pozzi ha señalado que el conflicto sobre la enseñanza secundaria produjo un cambio de papeles que llevó a los católicos a defender la libertad de enseñanza y a los liberales el monopolio de la educación ${ }^{5}$. Por todo ello, parece necesario detener nuestra atención en las posturas defendidas por algunos de los más conspicuos representantes del partido católico, para contrastar desde esta posición las posturas asumidas por Tocqueville. En el otro lado del espectro político interesa también traer a colación los argumentos ofrecidos por los defensores de la Universidad a través de las intervenciones de algunos de los liberales más influyentes de su tiempo, como es el caso de Víctor Cousin o Adolphe Thiers.

Aun cuando su participación en el debate no fue tan relevante como la de otros politicos como Montalembert o el propio Thiers, Tocqueville se sintió directamente interpelado por el conflicto escolar y la discusión pública que su resolución despertó en Francia. No podia ser de otra manera pues, lo que se debatía en el fondo era el papel reservado a la Iglesia en la sociedad liberal, es decir, dentro de un marco histórico que ya no era el del Antiguo Régimen. Además de una intervención extensa en el mes de enero de 1844 en respuesta al anuncio del nuevo proyecto de ley sobre enseñanza secundaria, Tocqueville participó en el debate sobre la libertad de enseñanza a partir de una serie de artículos publicados en el periódico Le Commerce entre julio y diciembre de ese mismo año. Y formó parte de la Comisión creada por la Cámara de Diputados para tratar de este asunto.

\section{PREPARACIÓN DEL DEBATE: LAS TESIS CATÓLICAS}

En el discurso de apertura de la sesión parlamentaria de 1844 , celebrada el 27 de diciembre anterior, el rey había anunciado la presentación de un proyecto de ley sobre la instrucción secundaria. Los términos en que el anuncio fue hecho apuntaban ya a la búsqueda de un compromiso entre los defensores de la Universidad y, en general, del control del Estado sobre la enseñanza, y la de aquellos, en su mayoría católicos, que reclamaban una libertad amplia en esta

\footnotetext{
${ }^{5}$ Regina Pozzi, Scuola e società nel dibattito sull'istruzione pubblica in Francia (1830-1850), La Nuova Italia, Florencia, 1969, p. 33.
} 
materia. En efecto, Luis Felipe se refirió en su alocución a la próxima presentación por el gobierno de un proyecto de ley que haría realidad lo propuesto por la Carta constitucional de 1830 sobre libertad de enseñanza al tiempo que mantendria la autoridad y la acción del Estado sobre la instrucción pública ${ }^{6}$.

En efecto, la Carta de 1830, en su artículo 69.8 establecía que en el plazo más corto posible de tiempo se expediria una ley relativa a la instrucción pública y a la libertad de enseñanza. Si bien en 1833, bajo el liderazgo de Guizot, el gobierno habia logrado la aprobación de una ley que regulaba la instrucción primaria, la instrucción secundaria todavía seguía el modelo de monopolio universitario establecido por Napoleón. A la cabeza de la Universidad estaba el Grand-Maistre, al mismo tiempo ministro de Instrucción, asistido por un Conseil de l'Université. A su vez la Universidad se dividia en circunscripciones o academias, dirigidas por un rector del que dependian dos órdenes de funcionarios: los administradores y los docentes.

La instrucción secundaria se impartía en liceos y colegios comunales. De esta manera a la Universidad se le reconocía el monopolio en la enseñanza secundaria: ninguna escuela ni instituto de instrucción podía existir fuera de la Universidad o sin su autorización. Solo la Universidad concedia los grados y títulos para enseñar oficialmente ${ }^{7}$.

Durante la década de los treinta y comienzos de los cuarenta, no habían faltado diferentes intentos de modificar el modelo napoleónico dando entrada, aunque de manera siempre limitada, a la libertad de enseñanza, cumpliendo así con lo dispuesto en la Carta constitucional de la monarquía de Julio. En 1836 y 1841, Guizot y Villemain habian presentado respectivamente sendos proyectos de ley sobre enseñanza secundaria, pero sin éxito alguno. El último proyecto había reconocido el principio de libertad de enseñanza, si bien condicionaba la autorización para abrir centros educativos libres al cumplimiento de determinados requisitos de grados universitarios y capacidad, y los sometía a la fiscalización del Estado. Además, suprimía la limitación en el número de estudiantes de los seminarios menores introducida por una ordenanza de 1828, al tiempo que sometía esos centros al régimen de derecho común, que incluía tanto el cumplimiento de determinados requisitos para el personal docente, como su sujeción a la vigilancia del Estado y a su jurisdicción en materia educativa. Sin embargo la oposición de gran parte de los obispos al proyecto forzó su retirada ${ }^{8}$.

De esta manera, cuando Villemain presentó el 2 de febrero de 1844 su nuevo proyecto de ley, la opinión pública llevaba ya varios años agitada. La presentación de la primera ley por Villemain habia encendido el debate entre partidarios y detractores de la Universidad, o entre los que defendian un control estricto por parte del Estado del ámbito educativo y quienes reclamaban la aplicación del principio de libertad de enseñanza consagrado en la Constitución. Desde 1841 se

${ }^{6}$ Louis Grimaud, Histoire de la liberté d'enseignement en France depuis la chute de l'Ancien Régime jusqu'a nos jours, Imprimerie Allier Frères, Grenoble, 1898, p. 326.

7 Regina Pozzi, Scuola e società, op. cit., pp. 16-17.

8 A. Debidour, Histoire des rapports de l'Église et de l'État en France de 1789 a 1870, Félix Alcan Editeur, París, 1898, p. 447. 
habían multiplicado los panfletos y artículos en los principales periódicos a favor y en contra de la Universidad. Lo que numerosos católicos achacaban a la Universidad no era solo el monopolio en la enseñanza, sino sobre todo la difusión de ideas contrarias a la religión católica. La filosofía entonces reinante en la Universidad era en buena medida el eclecticismo de Victor Cousin, que algunos identificaban con los errores panteístas, o con la irreligión y el racionalismo ${ }^{9}$. Lo que se hallaba en juego para las diferentes partes en conflicto era algo más que una cuestión de libertades: lo que se jugaban era la visión del mundo en la que se formarian las jóvenes generaciones de franceses. En este sentido, conviene no minusvalorar las críticas lanzadas desde el bando católico a la filosofia enseñada en la Universidad y a la orientación general de los estudios. Si bien en sus expresiones concretas carecieran en muchos casos de moderación, respondian a una problemática sentida profundamente por muchos católicos, y en primer lugar por la jerarquía eclesiástica. Al mismo tiempo conviene recordar que, hasta la Tercera República, la religión era enseñada en las escuelas y colegios públicos, de manera que los eclesiásticos tenian también un lugar dentro de los establecimientos dependientes de la Universidad ${ }^{10}$.

Por otra parte, también entre los católicos era posible diferenciar posiciones. Algunos como Louis Veillot o Montalembert denunciaban con especial radicalidad las enseñanzas que se impartian en la Universidad. Otros, entre los que se encontraban el obispo de Langres, monseñor Parisis, Lacordaire o el arzobispo de París, monseñor Affre, adoptaron posiciones más moderadas ${ }^{11}$. Este último publicó en 1843 unas "Observations sur la controverse elevée a l'occasion de la liberté d'enseignement" que trataban de defender con moderación la implantación de un verdadero régimen de libertad religiosa, al tiempo que se desmarcaba de las injurias lanzadas por algunos eclesiásticos contra la Universidad y contra algunos docentes. En su opinión, un cuerpo de 50.000 hombres, el clero, no podía ser responsable de la actuación de algunos pocos ${ }^{12}$. En este sentido, el arzobispo trataba de deshacer la imagen de una Iglesia en lucha contra el Estado, o contra la parte de él representada por la Universidad.

Desde el comienzo de su escrito, el arzobispo de París trataba de situarse como intentaría el propio Tocqueville- en un justo medio entre dos extremos: la reclamación de una libertad de enseñanza sin límites ni garantías, y su total negación a través del monopolio concedido a la Universidad en este ámbito ${ }^{13}$.

${ }^{9}$ Louis Liard, L'enseignement superieur en France, 1789-1893, II, Armand Colin et Cie, París, 1893, p. 191

10 Sonia Chabod, Éducation civique, op. cit., p. 247.

11 Precisamente en 1843, un año antes de la primera intervención de Tocqueville sobre la libertad de enseñanza en la cámara de los diputados, Louis Veuillot entró en el periódico L'Univers religioux para defender la causa ultramontana y luchar a favor de la religión y la libertad de enseñanza. Debidour, Histoire, op. cit., p. 454. Sobre las diferentes posiciones de los católicos en la prensa con relación a las libertades modernas vid. Sylvain Milbach, Les Catholiques Liberaux et la Presse entre 1831 et 1855, Le Mouvement Social, no 215, 2006, pp. 9-34. Y con referencia concreta al debate sobre la educación, Joseph N. Moody, The French Catholic Press in the Education Conflict of the 1840's, French Historial Studies, no 7-3, 1972, pp. 394-415.

12 M. l'Archevèque de Paris (Denis Auguste Affre), Observations sur la controverse elevée a l'occasion de la liberté d'enseignement, Librairie d'Adrine Le Clere et Cie, Paris, 1843, p. 26.

13 Ídem, p. 17. 
Además, su postura era presentada como la mayoritaria entre el episcopado francés, con apenas dos o tres excepciones ${ }^{14}$. Los obispos -argumentaba monseñor Affre- habían callado durante once años y solo alzaron su voz cuando vieron aplicar a los seminarios menores un régimen sumamente restrictivo de la libertad bajo la cobertura de su inclusión en un derecho común que asumía el régimen establecido por las ordenanzas de $1828^{15}$. El arzobispo reconocía al Estado el derecho de supervisar las escuelas, corregir los desórdenes y establecer ciertas garantias para su apertura y funcionamiento. El problema, sin embargo, era que las condiciones establecidas por los diferentes proyectos no garantizaban nada: ni la prueba de capacidad moral expedida por el alcalde de la localidad servía para garantizar la probidad de quienes pretendian regentar un establecimiento educativo, ni tampoco los requisitos de grados servian para algo más que para demostrar la mejor o peor memoria de los candidatos. Mayores garantias representaban para monseñor Affre las que podía dar el Consejo general a quien quisiera dirigir una escuela en el espacio de un departamento, el Consejo municipal al que lo quisiera hacer en un municipio, o el obispo al sacerdote que pretendiera dirigir una escuela particular. En estos casos, no solo se podría valorar la capacidad del candidato, sino el desempeño realizado hasta ese momento, sus virtudes, etc. Y en caso de error, el legislador podría adoptar las medidas oportunas para cerrar estos establecimientos. En este sentido, el requisito de grados no solo no servía para probar la idoneidad para dirigir establecimientos educativos, sino que se había introducido con la finalidad de entorpecer el desempeño de estas funciones por el clero ${ }^{16}$.

En opinión del arzobispo de París, lo que latía en el fondo de las medidas incorporadas a estos proyectos era la convicción generalizada de que, si se concedian facilidades a los sacerdotes para dirigir escuelas, la competencia con la Universidad sería más fuerte y, una vez apoderados de la educación, serían dueños de la sociedad. Por ello, monseñor Affre trataba de tranquilizar a quienes temían una invasión del espacio político por parte del clero. La Iglesia -y en esto coincidia como veremos con Tocqueville- carecía del poder e influencia de otro tiempo: habia sido excluida de todas las asambleas, desde las más pequeñas como los consejos municipales hasta la más elevada, la Cámara de los Pares. Tampoco tenía propiedades, ni siquiera las casas donde habitaba ni los templos donde rezaba ${ }^{17}$.

A pesar de la sospecha levantada por algunos de que el celo de los obispos por la libertad ahora reclamada no era sincero, monseñor Affre insistía una y otra vez en que lo único que solicitaba era la libertad de los padres a que sus hijos fueran educados en sus mismas convicciones morales. No dejaba de resultar paradójico que los que se pretendian amigos de la libertad defendieran el monopolio universitario. Eran los católicos los que en el ámbito de la enseñanza se mostraban más liberales:

“¡Os tenéis por apóstoles de todas las libertades; nos denunciáis como enemigos irreconciliables y sin embargo nos negáis la libertad más esencial; sospecháis de la

\footnotetext{
14 Ídem, p. 21.

15 Ídem, pp. 4-9.

16 Ídem, pp. 65-69.

17 Ídem, pp. 71-73.
} 
sinceridad de nuestro celo; probad la sinceridad del vuestro! Vosotros poseéis la libertad de la que nosotros estamos privados: ¿por qué nos la negáis si es verdad que sois devotos de ella?"18

Para el arzobispo, la enseñanza moral iba intimamente ligada a la religiosa, de manera que no correspondía al Estado impartirla, sino a los ministros de las diferentes confesiones, también en la Universidad. Cada confesión poseía su propio código moral, pero no el Estado. Éste se regía en su actuación por los principios de una moral universal que incidía solo en los actos externos. Por el contrario, la moral cristiana se proyectaba sobre todas las acciones, muchas de las cuales escapaban al imperio de las leyes ${ }^{19}$. Por ello, podía afirmarse que las instituciones laicas tenían necesidad de la enseñanza proporcionada por el clero, pero no al revés. Con todo, el arzobispo se apresuraba a señalar que no pretendía ningún derecho exclusivo para la Iglesia, sino tan solo la libertad de prestar sus servicios a quienes lo requirieran. En cualquier caso, se mostraba favorable a la colaboración en la enseñanza entre maestros laicos que dieran la instrucción científica y literaria, y clérigos que impartieran la enseñanza moral y religiosa ${ }^{20}$.

Por otra parte, el arzobispo no dejaba de denunciar las enseñanzas anticristianas que los estudiantes recibian en los cursos de filosofia y que contrastaban en aspectos fundamentales con las doctrinas impartidas por los capellanes. En este punto, monseñor Affre se sumaba a una denuncia común en la crítica que desde las filas católicas se dirigía contra la Universidad ${ }^{21}$.

El arzobispo de París terminaba su escrito reclamando una discusión tranquila y educada de la libertad de enseñanza y tranquilizando a quienes temían la influencia del clero en la vida política. Las costumbres -señalaba monseñor Affre- habían cambiado y la ascendencia sobre las conciencias no abarcaba en modo alguno la dirección de los asuntos políticos o administrativos de los católicos ${ }^{22}$.

Al tiempo que el obispo de París publicada sus "Observaciones", Montalembert, líder del partido católico, publicaba ese mismo año un folleto titulado "Devoir des catholiques dans la question de la liberté d'enseignement"23. Merece la pena detenerse brevemente en los argumentos empleados por este autor, dado su protagonismo en los debates sobre la libertad de educación y su carácter representativo del ultramontanismo católico. Su postura nos ayudará por un lado, a apreciar las diferencias de tono más que de fondo en las filas católicas y, por otro, a situar el discurso de Tocqueville de enero de 1844 en su debido contexto. De hecho, existen indudables coincidencias entre las tesis que

18 "Vous vous donnez pour les apôtres de toutes les libertés; vous nous dénoncez comme leur irreconciliables ennemis et cependant vous nous refusez la plus essentielle! Vous suspectez la sincérité de notre zéle: prouvez la sincérité du vôtre. Vous possédez la liberté dont nous sommes privés: pourquoi nous la refusez-vous, s'il est vrai que vous lui soyez dévoués?". Ídem, p. 81.

19 Ídem, p. 39.

20 Ídem, p. 49.

${ }^{21}$ Ídem, pp. 55-56.

22 Ídem, p. 84.

23 Le Comte de Montalembert, Devoir des catholiques dans la question de la liberté d'enseignement, Au Bureau de l’Univers, París, 1843. 
los seguidores del partido católico llevaban defendiendo desde los tiempos de su colaboración en el periódico L'Avenir y las asumidas por Tocqueville.

En efecto, a las pocas semanas de aparecer en 1830, y con la finalidad de clarificar entre sus lectores la posición ideológica que defendian, este periódico católico dirigido por Lamennais y en el que participaban, entre otros, Montalembert y Lacordaire, resumía su programa en la defensa de las siguientes seis libertades: libertad de conciencia o de religión, libertad de enseñanza, libertad de prensa, libertad de asociación, libertad o, mejor dicho, universalización del sufragio y libertades locales ${ }^{24}$. Con relación a la libertad de enseñanza, L’Avenir reclamaba el fin del monopolio universitario y la aplicación de lo dispuesto en la Carta de 1830. Presentaba además esta libertad como la primera libertad de la familia, sin la cual la libertad religiosa y la libertad de opinión quedarian vacias de contenido.

Tras la condena de L'Avenir por el Papa, y la deriva de Lamennais hacia posiciones heterodoxas desde el punto de vista católico, Montalembert asumió el liderazgo de lo que con el tiempo vendría a denominarse el partido católico. El régimen liberal instaurado por la monarquía orleanista permitía asumir las libertades constitucionales y ponerlas al servicio de la libertad de la Iglesia. Y una de ellas, posiblemente la más importante desde el punto de vista del mantenimiento de la fe religiosa en el pueblo, era la libertad de enseñanza. Para lograr su implantación nació propiamente el partido católico, según afirmaría Falloux algunos años más tarde ${ }^{25}$. No es extraño, por ello, que aunque Tocqueville mantuviera siempre un gran recelo hacia este grupo de católicos, sus postulados teóricos coincidieran en numerosos puntos.

En su escrito de 1843, Montalembert asumía una determinada interpretación de la historia de Francia que se remontaba hasta el rey Clodoveo. Desde entonces y por más de mil años, Francia había sido fiel a la religión católica. Sin embargo, la obra intelectual promovida por la Ilustración habia ido despojando a la nación de su fe. En esta tarea, la Universidad había desempeñado un papel de especial protagonismo. En efecto, Montalembert comenzaba su escrito denunciando el estado de irreligión oficial en que había caído la nación y acusando a la educación pública ejercida en régimen de monopolio por el Estado de ser la principal causante de la irreligiosidad del pueblo francés. En la Universidad veía Montalembert "la fuente donde sucesivas generaciones beben el veneno que deseca en su raíz la disposición natural del hombre a servir a Dios y adorarlo" 26 .

Una vez diagnosticado el problema, Montalembert pasaba a proponer la solución. No era posible ya recuperar la Francia católica de los siglos comprendidos entre Clodoveo y Luis XIV. Pero sí se podía evitar a los hogares cristianos la exposición a doctrinas anticristianas, destruyendo el monopolio napoleónico de la Universidad. Para ello, Montalembert apelaba a la libertad de educación y a la libertad religiosa consagrada en la Carta ${ }^{27}$. Parecía claro, pues,

24 Marcel Prélot y F. Gallouedec Genuys, Le liberalisme catholique, A. Colin, París, 1969 , p. 84.

25 Comte de Falloux, Le parti catholique, ce qu'il a été, ce qu'il est devenu, Ambroise Bray Ed., París, 1856, p. 8.

26 Montalembert, Devoir, op. cit., pp. 14-15.

27 Ídem, p. 19. 
que con independencia del valor que el líder del partido católico otorgase a la libertad en sí misma, esta aparecía principalmente como un medio para la consecución de un bien mayor: la preservación de la fe en Francia.

Montalembert criticaba a aquellos que identificaban la Universidad con el Estado y veían en la educación una función pública como lo era la magistratura o el ejército. Se trataba una vez más del triunfo de la sociedad nueva, que habiendo despojado al individuo de todas las corporaciones lo arrojaba en manos de la única subsistente: el Estado. Por el contrario, el derecho y el deber de enseñar la fe no radicaban solo en la Carta constitucional sino en el mandato mismo de Jesucristo. Para Montalembert la enseñanza no pertenecía al ámbito temporal sometido al Estado sino al religioso. Junto a estos argumentos tanto de tipo constitucional como confesional, Montalembert apelaba al ejemplo de otras naciones liberales, como Bélgica o Estados Unidos, donde regía un verdadero sistema de libertad de enseñanza ${ }^{28}$. En este punto no dejaba de citar la Democracia en América de Tocqueville para poner de manifiesto que en este clima de libertad la mayor parte de la educación corría de parte del clero. En Francia, sin embargo, el Estado pretendia suplir a la Iglesia y a las familias, "estos dos hogares sagrados de la libertad moral del género humano" imponiendo una uniforme mediocridad ${ }^{29}$. En definitiva, concluia Montalembert, el Estado ocupaba ahora el lugar de la Iglesia en su deseo de formar a los ciudadanos ${ }^{30}$. Este era sin duda el tema de fondo que latía en la polémica sobre la enseñanza. Durante siglos, la formación de la juventud había sido tarea exclusiva de la Iglesia en Francia. Con la irrupción de la Revolución y la implantación de lo que tanto liberales como contrarrevolucionarios llamaban sociedad nueva, el papel de la Iglesia era puesto en entredicho, así como su capacidad para dotar a los futuros ciudadanos del espíritu liberal que los nuevos tiempos exigian. A la vez, resultaba incongruente negar a la Iglesia en nombre de estos mismos principios liberales su derecho de concurrir, con la Universidad, a la educación de las nuevas generaciones. Como lo era también negar a los padres el derecho de elegir para sus hijos la educación moral que entendieran más idónea para su desarrollo.

Aun cuando el escrito de Montalembert coincidiera en sus tesis fundamentales con el del arzobispo de París, el tono empleado era bastante diferente. De hecho, Montalembert no tenía reparo alguno en referirse a las intervenciones de otros católicos, como el cardenal De Bonald y el obispo de Belley, que no habian dudado en hablar de "cátedras de pestilencia" en sus criticas a la Universidad.

Pensando en el proyecto de ley que en la siguiente sesión se presentaría, Montalembert se adelantaba a denunciar la prohibición impuesta a las órdenes religiosas de dedicarse a la enseñanza, asegurando así de hecho el monopolio de la Universidad ${ }^{31}$. Para el líder del partido católico, la regeneración de la enseñanza solo podría venir de la mano de las congregaciones religiosas y entre ellas de los jesuitas.

\footnotetext{
28 Ídem, p. 26.

29 "ces deux foyers sacrés de la liberté morale du genre humaine". Ídem, p. 32.

30 Ídem, p. 34.

31 Ídem, p. 57.
} 
Montalembert terminaba su escrito convocando a todos los católicos a la lucha a favor de la libertad religiosa, con independencia de sus otras ideas politicas; a participar en las elecciones con el propósito de avanzar en esta causa común ${ }^{32}$. Y a llevar esa lucha también a la prensa y al ejercicio del derecho de petición al parlamento ${ }^{33}$.

El escrito de Montalembert era un verdadero manifiesto de guerra, si bien pacífico en la medida en que los medios que llamaba a utilizar eran los facilitados por el régimen constitucional iniciado por la monarquía de julio.

De la lectura del escrito de Montalembert se deduce con bastante claridad -como ya adelantamos- que no era solo la libertad en sí misma, sino sobre todo sus consecuencias lo que importaba al líder del partido católico. El objetivo final de su lucha por la libertad de enseñanza no era otro que preservar la fe de los jóvenes católicos. La libertad era la puerta que la Constitución de 1830 ofrecía para lograr que la influencia intelectual de la Universidad quedara reducida al minimo posible. Convencido de la imposibilidad de restaurar la Francia católica del Antiguo Régimen, edificada en torno a la unidad en la fe, lo único que quedaba era conservar, en un clima intelectual que entendía contrario a las verdades de la religión revelada, la fe católica de las jóvenes generaciones. Y para ello, resultaba necesario que las congregaciones religiosas pudiesen adquirir el protagonismo que les correspondía en el ámbito de la educación.

Sin embargo, y sin contradecir lo que acabamos de señalar, lo cierto es que en lo relativo a la libertad de enseñanza, la postura propiamente liberal era defendida por el partido católico, incluidos los más fervientes ultramontanos. Y, por contraposición, una parte del pensamiento liberal, por miedo a la influencia del clero en la enseñanza, apoyaba medidas claramente limitadoras de esta libertad en beneficio de la Universidad. Frente a unos y otros, tratando de conciliar el espíritu de religión con el espíritu de libertad, Tocqueville trató de mediar en el conflicto buscando un punto medio entre dos extremos.

\section{LA DISCUSIÓN DE L'ADRESSE DE 17 DE ENERO DE 1844}

Cuando Tocqueville intervino en la Cámara de diputados en defensa de la libertad de enseñanza, el segundo proyecto de ley de Villemain sobre la instrucción secundaria todavía no había sido presentado. Sin embargo, la guerra entre los partidarios de la Universidad y sus detractores, o entre los que atacaban la religión y los que defendian la libertad de enseñanza ya se había desatado. Y esta guerra a los ojos de Tocqueville era peligrosa. En una carta de 15 de noviembre de 1843 a su amigo Corcelle, Tocqueville había escrito que su principal objetivo al entrar en politica era conciliar el espíritu de religión con el espiritu de libertad, esto es, "la sociedad nueva con la Iglesia"34. En esta misma

32 Ídem, pp. 66-67.

33 Ídem, pp. 69-70.

34 "La question religieuse me préoccupe comme vous; elle fait plus, elle m'afflige profondément. L'un de mes rêves, le principal peut-être en entrant dans la vie politique, était de travailler à réconcilier l'esprit libéral et l'esprit de religion, la société nouvelle et l'Église". Oeuvres Complètes Gallimard (en adelante OC), XV-1, p. 173. 
carta, Tocqueville manifestaba su desesperación. En su opinión, esta reconciliación, tan necesaria tanto para la libertad como para la moralidad, le parecía en esos momentos irrealizable. Y la culpa de haber llegado a semejante situación de enfrentamiento correspondia principalmente al clero, pues en lugar de limitarse a reclamar la aplicación del derecho común al ámbito de la enseñanza había mostrado su deseo de dominar toda la educación y dirigirla ${ }^{35}$.

En una carta dirigida a su hermano apenas dos semanas después, Tocqueville volvía sobre los mismos argumentos ${ }^{36}$. Por un lado, se mostraba indignado con la guerra que algunos periódicos estaban llevando a cabo contra el clero y la religión, y lamentaba el origen de la tormenta que había cambiado el sentido de la opinión pública en Francia anteriormente favorable al clero y a la enseñanza religiosa. El problema no radicaba en la justicia de la causa en sí misma, pues Tocqueville reconocía que la razón en este asunto correspondía sustancialmente al clero, sino en el modo en que este había tratado de defender su posición. En lugar de defender la postura constitucional que le era favorable y reivindicar con base en el derecho común su derecho a enseñar, similar al de cualquier otro ciudadano, el clero había reclamado la dirección de la educación como si de un derecho inherente a la Iglesia se tratase. Y más aún, habian tratado de mostrar que la Universidad no era digna de enseñar, levantando contra ellos todas las pasiones filosóficas. El resultado había sido no solamente la tempestad anticlerical desatada en los principales periódicos y en las Cámaras, sino el alejamiento de la misma libertad de enseñanza que reclamaban ${ }^{37}$.

La crítica de Tocqueville era cierta solo en parte, pues no faltaban en las filas católicas defensores de la libertad, que con base en el derecho común reclamaban el derecho de la Iglesia a enseñar. Podía incluso afirmarse que la causa de la libertad habia cambiado de partido y era defendida, al menos en parte, por los defensores de la religión, como acabamos de ver en el caso del conde de Montalembert y del arzobispo de París.

La preocupación de Tocqueville era doble. Por un lado, le preocupaba una posible alianza entre el poder eclesiástico y el gobierno en perjuicio tanto de la libertad de conciencia como de la libertad política. Por otro, también le inquietaba que los ataques furibundos a la Universidad por una parte del clero y de laicos católicos provocase, como ya estaba sucediendo, un movimiento de reacción que difundiera efectivamente el odio a la religión en Francia. Y dado que la causa de la libertad iba ligada en el pensamiento de Tocqueville a la causa de la religión,

35 OC, XV-1, p. 173. En esta misma carta, afirmaba la existencia en el catolicismo de un "espiritu intratable que no puede vivir en ninguna parte si no es el dueño". Aunque manifestaba su convicción de la necesidad de sostener el catolicismo en Francia, por ser la religión mayoritaria, al mismo tiempo mostraba su escepticismo acerca de la posibilidad de que el catolicismo llegara algún día a aceptar la nueva sociedad. Ídem, p. 174.

36 Tocqueville a Édouard, 6 de diciembre de 1843: “J'aborde la session tristement. L'état de la question religieuse me cause surtout un profonde douleur. Mon plus beau rève en entrant dans la vie politique, c'était de contribuer à la réconciliation de l'esprit de liberté et de l'esprit de religion, de la société nouvelle et du clergé”. Lettres choisies. Souvenirs. 1814-1859, edición de François Melonio y Laurence Guellec, Gallimard, París, p. 543.

37 Ídem, pp. 543-544. 
esta reacción anticlerical resultaba enormemente peligros ${ }^{38}$. Por ello, manifestaba a su amigo Corcelle la esperanza de que el gobierno no presentase otra ley de educación hasta que los ánimos se calmasen. Pero sus esperanzas eran vanas, pues -como hemos visto- en el discurso de apertura de las sesiones parlamentarias, el rey había adelantado la próxima presentación de una ley sobre enseñanza.

En una clara referencia a su experiencia americana, Tocqueville recordaba en su respuesta a la Adresse en la Cámara de Diputados que en los pueblos libres la libertad está enraizada en las creencias: "la libertad es menos hija de las instituciones que de las costumbres (moeurs), y las costumbres son hijas de las creencias" 39 . Sobre esta cuestión se habia extendido ya extensamente en la Democracia en América ${ }^{40}$. La consecuencia de esta íntima relación entre creencias (religiosas), costumbres (moeurs), instituciones y libertad era que las creencias religiosas debian preservarse, pues eran necesarias a un pueblo libre y todavía más a una nación democrática, como era el caso de Francia ${ }^{41}$. Las libertades no eran presentadas por tanto en su aspecto meramente formal, sino enraizadas en una tradición en el seno de la cual cobraban vida.

Cuando Tocqueville habla de creencias quiere dejar claro que se refiere a las creencias religiosas, de una religión positiva, no a la creencia en el bien de la humanidad o a otras creencias de tipo deísta. Citando a Portalis, Tocqueville recordaba que "una moral sin dogma es como una justicia sin tribunales". No bastaba la mera filantropía para elevar el nivel moral de un país. La libertad debía enraizarse en lo más profundo de las creencias y de las costumbres. Y para ello se requería la fuerza de la religión. En Francia esa religión era en primer lugar la católica, por ser la mayoritaria, pero en la causa de la libertad debía empeñarse también el clero de las demás confesiones religiosas. En este sentido, lo que Tocqueville temía era que la querella que desde hacía un tiempo enfrentaba a católicos y liberales de diferente signo condujera a una indiferencia religiosa y con la ruina de la religión, se arruinase también la libertad ${ }^{42}$.

\footnotetext{
38 Ídem, p. 174. En una carta anterior a Corcelle, de 12 de octubre de 1843, Tocqueville acusaba al clero de ser imprudente e incluso calumnioso en sus ataques a la Universidad. OC, XV-1, p. 169. En otra carta, esta vez a Beaumont de 27 de diciembre de 1843, Tocqueville escribia: "les fautes du clergé sont trop grandes pour que je cherche à lutter contre le courant qui se dirige contre lui et par contrecoup contre la religion même". OC, VIII-1, p. 526. Sin embargo, apenas transcurrido un mes, Tocqueville entró de lleno en el debate sobre la libertad de enseñanza.
}

39 “...la liberté est bien moins fille des institutions que des moeurs, et que les moeurs sont filles des croyances". Discussion de l'Adresse, 17 de enero de 1844, OC, III-2, p. 494.

40 Vid. A. De Tocqueville, De la démocratie en Amérique, tomo I, segunda parte, cap. IX. Utilizo la edición de Eduardo Nolla, Librairie Philosophique J. Vrin, París, 1990. Y en la introducción a este primer volumen había escrito "qu'on ne peut établir le règne de la liberté sans celui des moeurs, ni fonder les moeurs sans les croyances”. Ídem, p. 13.

41 Discussion de l'Adresse, 17 de enero de 1844, OC, III-2, p. 494. Para Tocqueville ningún pueblo podía prescindir de una religión positiva. El cristianismo constituía, además, el fundamento de la moral moderna, por lo que su preservación resultaba más exigible si cabe. Tocqueville a Arthur de Gobineau, 2 de octubre de 1843, OC, IX, pp. 58-59.

42 Discussion de l'Adresse, OC, III-2, p. 495. 
Las notas tomadas para preparar este discurso ilustran suficientemente acerca de las cuestiones fundamentales sobre las que Tocqueville pretendia articular su intervención. En uno de los epígrafes titulado "Faltas del poder", Tocqueville incluia como la primera: "Cuestiones irritantes dejadas sin decidir". Estas cuestiones capaces de agitar la opinión pública eran tres: la enseñanza, las ordenanzas y leyes relativas al clero y las congregaciones religiosas ${ }^{43}$. Sobre estas tres cuestiones se pronunciaría en el discurso. El tema es de sumo interés, pues Tocqueville adelantaba aquí algunos de los problemas que abordaría mas adelante en sus escritos periodísticos y en sus intervenciones ante la Cámara.

Lo que preocupaba a Tocqueville, más que la libertad de enseñanza en particular, de la que poco podía decir, pues el nuevo proyecto de ley todavía no habia sido presentado, era el interés del gobierno en someter al clero, en ganarse su favor y convertirlo en instrumento de gobierno. Tocqueville parece referirse en este punto a la persecución dirigida por el Estado contra el culto de algunos grupos protestantes no reconocidos. Había violado así -en palabras de Tocqueville- una de las más grandes libertades conquistadas en 1789, la libertad religiosa ${ }^{44}$. A este peligro se había referido ya en una carta a Corcelle. Este nuevo entendimiento entre el Estado y la Iglesia, según Tocqueville, podía resultar extremadamente nociva a la libertad, "uno ayudando a restringir la libertad de conciencia y el otro la libertad politica"45.

Con este modo de proceder se ponía en peligro uno de los principios más queridos de Tocqueville: la separación no solo de la Iglesia y del Estado, sino también de la religión y la política. No se trataba de proteger al Estado de un posible gobierno clerical, sino más bien de proteger a la religión de su utilización por el Estado. Si la religión, como acabamos de ver, constituía un baluarte indispensable para la libertad, cualquier declive de aquella derivada de su alianza con el poder politico resultaría sumamente nefasta para la sociedad. En este sentido, afirmaba Tocqueville que la Revolución de Julio había realizado un gran servicio a la religión, al separarla de la política ${ }^{46}$.

Las ideas defendidas por Tocqueville en esta primera intervención no eran nuevas. Tampoco la situación que se estaba creando con el debate en torno a la libertad de educación era del todo inédita. Los males que Tocqueville pretendía conjurar se habían experimentado ya de alguna manera durante la Restauración. La unión reeditada del trono y del altar durante este período -había escrito Tocqueville a Lord Radnor- había provocado el renacimiento en Francia del espíritu de Voltaire con críticas a los ministros de la religión y al propio cristianismo. Por su parte, convertido el clero en partido politico, favorable al poder absoluto del rey, los liberales habian renegado de la religión, movidos por sus principios políticos. Y en opinión de Tocqueville, estos odios religiosos habían terminado por provocar la caída de los Borbones. El cambio de régimen de la monarquía de Julio había transformado sustancialmente la situación. Desligado de sus lazos con el poder político, la religión habia vuelto a ganar influencia entre

\footnotetext{
43 Esquisse $d u$ discours sur l'Adresse, OC, III-2, pp. 505-506.

44 Discussion de l'Adresse, OC, III-2, p. 491.

45 Tocqueville a Corcelle, 15 de noviembre de 1843, OC, XV-1, p. 174.

46 Discussion de l'Adresse, OC, III-2, p. 490.
} 
la población y especialmente entre los jóvenes. La prédicas de Lacordaire en Notre Dame eran seguidas por miles de ellos. Se trataba de una situación nunca vista durante la Restauración ${ }^{47}$.

Sin embargo, el problema ahora se volvía a plantear con motivo de la discusión de la libertad de enseñanza y las críticas feroces dirigidas por una parte del clero a la Universidad. Con todo, la situación no era exactamente la misma. No parecía que la Iglesia estuviese en posición de controlar al Estado. Así, frente a quienes se alarmaban ante una posible influencia del clero en el gobierno del Estado, Tocqueville defendia que el problema no era la influencia del clero en el gobierno sino más bien lo contrario. En este sentido, llama la atención que Tocqueville pasara a continuación a afirmar que el Concordato había colocado al clero en una "dépendance salutaire du pouvoir"48. En efecto, la nacionalización de los bienes eclesiásticos y la creación de una partida presupuestaria para el mantenimiento del clero y del culto había terminado con la independencia económica y también en parte política que caracterizaba al clero del Antiguo Régimen. Desde esta perspectiva el clero no podía constituir ningún peligro para un Estado del cual dependia económicamente. Su influencia había pasado a ser fundamentalmente moral. Parece posible interpretar en este sentido la afirmación de Tocqueville relativa a la dependencia "saludable" del clero respecto del Estado. Responde -podría decirse- a una estrategia argumentativa dirigida a poner de manifiesto que el peligro no podía venir del clero, sino del propio gobierno.

Parece claro, pues, que la separación Iglesia-Estado no implicaba de hecho incomunicación entre las dos potestades. Al menos desde el punto de vista económico, la Revolución se había encargado de que esto no fuera así. Pero tampoco en otras cuestiones el Estado dejaba de ejercer un cierto control sobre la Iglesia. La pregunta, por tanto, no era si resultaba deseable esta separación, sino qué aspectos de la actividad externa de la Iglesia debian ser regulados por el Estado. Y en este punto, el problema radicaba en que parte de la legislación revolucionaria y post-revolucionaria en la materia no se aplicaba. Para Tocqueville esta situación era la peor posible, pues creaba quejas y falsas esperanzas de parte de unos y de otros. Resultaba preciso ejecutar esas leyes o suprimirlas, aunque su alegato quedaba ahi, sin mayores concreciones ${ }^{49}$.

Algo decía, sin embargo, de la legislación relativa a las congregaciones religiosas. Para Tocqueville el Estado no podía hacer depender de su mero querer la existencia de las congregaciones religiosas, aunque podia prohibir aquellas que considerara peligrosas para el Estado, del mismo modo que hacia con las asociaciones politicas. Pero esto no lo habia hecho, y ahora existian órdenes religiosas que no estaban ni permitidas ni prohibidas. De hecho, algunas congregaciones suprimidas por la Revolución habian sido restauradas, como los benedictinos o los dominicos, en el caso de estos últimos por obra de Lacordaire $^{50}$. Sin embargo, el problema principal se planteaba con los jesuitas, a quienes veladamente aludia Tocqueville al referirse a las órdenes peligrosas para

47 Tocqueville a Lord Radnor, 3 de mayo de 1835, en A. de Tocqueville, Lettres choisies, op.cit., pp. 321-325.

48 Discussion de l'Adresse, OC, III-2, p. 493.

49 Ídem, p. 490.

50 Ídem, p. 490, nota 2. 
el Estado. En este sentido, resulta dificil desde una perspectiva actual conciliar las tesis liberales de Tocqueville con su apoyo, al menos moral, a la prohibición impuesta sobre los jesuitas de reorganizarse en Francia. Sin embargo, conviene tener en cuenta la profundidad del prejuicio anti-jesuitico existente en Francia desde el Antiguo Régimen. En la narrativa liberal que hacia coincidir el inicio de la historia del avance de la libertad en Europa con la Reforma, los jesuitas hacian de contrapunto. En efecto, en esta narrativa, paradigmáticamente representada por la Historia de la Civilización en Europa de Guizot, los jesuitas ocupaban también un lugar destacado: eran las fuerzas del mal, del despotismo y del sometimiento a Roma que había que destruir para que el imperio de la libertad y las luces se hiciese realidad ${ }^{51}$. Tocqueville habia crecido en este ambiente intelectual y, por tanto, no parece extraño que participase de estos prejuicios ${ }^{52}$.

Tocqueville terminaba su alocución volviendo al tema señalado al comienzo. La discusión saludable sobre opiniones politicas había cedido paso a la guerra sobre cuestiones filosóficas y de conciencia. Y esto era peligroso.

La postura de Tocqueville solo podía ser compartida si, como él, se partía del presupuesto, expuesto en la Democracia en América, de que la libertad total en el ámbito político requería una fijeza igualmente absoluta de las verdades religiosas y morales. En este sentido, como bien ha explicado Battista, el liberalismo de Tocqueville era únicamente político: no constituía una Weltanshauung opuesta a la católica ${ }^{53}$. En el borrador que redactó para preparar su discurso este presupuesto de su pensamiento aparece expresado con especial claridad: "en lugar de la lucha natural y saludable de los partidos politicos, la querella que destruye los fundamentos del orden social e inquieta las conciencias"54. La religión aparecía así como ese fundamento sólido, indisponible para la voluntad humana, que permitía erigir sobre él un régimen de libertad. En este sentido, toda actuación que llevara a minar este fundamento se entendía perjudicial también para la libertad.

Sin embargo, para quien no compartiera estos planteamientos, la oposición a la discusión pública de problemas religiosos o filosóficos podía parecer incongruente. Así le pareció en particular al ministro de instrucción pública Villemain, que respondió de manera crítica a lo defendido por Tocqueville. El debate público sobre las cuestiones religiosas no era más que una consecuencia de la libertad de prensa55. En su contrarréplica, Tocqueville acusaba al gobierno de dejar en suspenso algunas cuestiones espinosas, como la libertad de enseñanza o la aplicación o reforma de las leyes relativas a las congregaciones

51 François Guizot, Histoire de la civilization en Europe, Didier, París, 1870, pp. 346-347.

52 Para justificar su postura, Tocqueville escribiría un año más tarde, en un artículo en Le Commerce de 3 de mayo de 1845, que los jesuitas habian sido expulsados de Europa por orden de príncipes católicos y suprimidos como congregación religiosa por mandato del mismo Papa. OC, III-2, p. 611.

53 Ana María Battista, Lo spirito liberale, op. cit., p. 44.

${ }^{54}$ Esquisse du discourse sur l'Adresse, OC, III-2, p. 505.

55 Discussion sur l'Adresse, OC, III-2, p. 495. 
religiosas. En este caso, la referencia a los jesuitas como congregación que podía ser peligrosa y por tanto susceptible de prohibición era más clara ${ }^{56}$.

La respuesta del ministro vino un mes después con la presentación de un nuevo proyecto de ley sobre instrucción secundaria. Su discusión en las Cámaras encendería aún más el debate fuera de ellas.

\section{EL SEGUNDO PROYECTO DE LEY VILLEMAIN}

En la exposición de motivos de la ley, el ministro Villemain trataba de fundamentar los derechos del Estado en materia educativa frente a quienes defendian que la tradición propia de Francia desde los tiempos antiguos había sido la de la libertad de enseñanza. Para ello, el ministro construía una narrativa alternativa que desde los primeros siglos de la era cristiana hasta la Revolución mostraba la creciente intervención del Estado en materia educativa. En una época tan temprana como el siglo XVI -según Villemain- la enseñanza superior se había secularizado completamente, a raíz de un decreto de Enrique IV de 1598 dirigido a la Universidad de París, que después se extendió a otras Universidades del reino. Además, muchas de las condiciones que la ley que ahora se presentaba establecía para abrir establecimientos docentes eran ya entonces requeridas, como los grados para desempeñar funciones docentes o la autorización previa.

En esta narrativa también encontraban su lugar los jesuitas, como una congregación religiosa que desde el principio había sido legalmente apartada de la enseñanza, a pesar de lo cual y hasta su expulsión de Francia en 1762 había logrado dirigir un número importante de centros educativos. Para ello se había servido de una bula pontificia del siglo XVI expedida en los términos más generales.

La finalidad de toda la argumentación era concluir que la Universidad imperial establecida por Napoleón especialmente a partir de la regulación de 1808 no era una novedad fruto del despotismo, sino que hundía sus raíces en la historia de Francia. Lo nuevo era el principio de libertad de enseñanza introducido por una ley de 1793, pero siempre con ciertas garantias, que aseguraban la supervisión de las autoridades públicas. En 1802 se estableció la necesidad de la autorización previa para abrir escuelas y así se recogió en leyes posteriores. Se recuperaba así un requisito que formaba parte de la historia de Francia. A continuación, la exposición de motivos pasaba a explicar el contenido de la ley que se proponía a las cámaras ${ }^{57}$.

Acorde con la politica de compromiso que caracterizaba el gobierno Guizot, la ley trataba de contentar a todos, no logrando al final contentar a ninguno. La ley permitía la apertura de instituciones educativas o internados, pero exigía unos determinados requisitos: un certificado de buenas costumbres expedido por el alcalde del municipio, un título de capacidad emitido por un jurado, una

\footnotetext{
56 "Pourquoi parmi ces congrégations ne choisissez-vous pas celles qui peuvent être útiles, et celles qui, suivant moi, ou plutôt celle, car il y en a une au moins, qui pourrait être dangereuse?”. Ídem, p. 500.

57 Discussion de la loi sur l'Instruction Secondaire, I, A l'administration du Moniteur Universel, París, 1844, pp. 1-14.
} 
declaración de no pertenecer a ninguna asociación o congregación religiosa no autorizada por el Estado, los diplomas de bachiller en letras y/o ciencias en función del tipo de institución que se pretendiera erigir, el reglamento interior y el programa de estudios proyectado y el plan del local donde se impartiría la docencia (arts. 3, 5 y 6). Reconocía como establecimientos de pleno ejercicio aquellos que dispusiesen de profesores con los mismos grados que los colegios reales o comunales (art. 9). Sometía a todos los establecimientos particulares de instrucción secundaria a la inspección del Estado (art. 11). La ley mantenía, además, los privilegios acordados a los seminarios menores, autorizando a presentar al bachillerato la mitad de los estudiantes que no siguieran la vocación religiosa. Si los profesores encargados de retórica, filosofia y matemáticas dispusieran de los mismo grados que los profesores de los establecimientos de pleno ejercicio, los estudiantes podrian ser presentados al examen de bachillerato, con los limites de número establecidos en la ordenanza de 1828 (art. $17)^{58}$.

Los católicos se opusieron al nuevo proyecto de ley, pues entendian que los requisitos para abrir un centro escolar eran demasiado gravosos. Se criticaba además que en el jurado que debía expedir el título de capacidad figurasen varios miembros de la Universidad, cuyo interés cabía pensar en principio contrario a los establecimientos particulares y, sobre todo, que se exigiera la declaración de no pertenecer a ninguna congregación no autorizada. Tampoco se veía con buenos ojos la sujeción de estos colegios a la vigilancia del Estado ${ }^{59}$. Por último, se criticaba la inclusión de la filosofia en el programa de estudio y que no se hubiesen suprimido los certificados de estudios para poder presentarse al examen de bachillerato, pues para adquirirlos se exigia haber seguido los cursos de retórica y de filosofía en un colegio real o comunal o en uno autorizado ${ }^{60}$.

La discusión del proyecto comenzó en la Cámara de los Pares el 21 de abril de 1844. Con anterioridad, la Cámara había nombrado una comisión para su análisis, que a su vez comisionó al duque de Broglie para la elaboración de un informe sobre el proyecto, que fue presentado el 12 de abril. No nos es posible reproducir íntegro el debate que duró 29 sesiones en la cámara de los pares ${ }^{61}$. Sin embargo, merece la pena detenerse aunque sea brevemente en la intervención de Víctor Cousin en la sesión del 21 de abril, con la que se inició el debate, pues representa suficientemente los argumentos de aquellos que defendian en mayor o menor medida el monopolio universitario de la educación. Por otra parte, planteaba el problema de la educación en toda su profundidad: lo que se estaba decidiendo era a quién correspondia la formación de la nación, esto es, de sus ciudadanos. Partiendo de la postura de Cousin y de otras figuras protagonistas del debate como Montalembert y Thiers, será posible interpretar la postura de Tocqueville defendida públicamente a través de la prensa a partir de julio de ese mismo año y dirigida a rebatir los argumentos de aquellos que, como

58 Los artículos de la ley relativos a los establecimientos no oficiales vienen reproducido en Louis Grimaud, Histoire, op. cit., pp. 327-333.

59 Ídem, pp. 334-336.

60 A. Debidour, Histoire des rapports, op. cit., p. 458.

61 Louis Grimaud, Histoire, op. cit., p. 339. 
Cousin, concebian la enseñanza como un poder público, susceptible de autorización previa, y no como un derecho natural, garantizado por la ley.

En efecto, Cousin comenzaba su exposición planteando precisamente esta cuestión: ¿era la enseñanza un derecho natural como la libertad de conciencia, o un poder público, como el de hacer justicia? Para el padre del eclecticismo, la enseñanza no era un derecho, sino un poder que se ejercita sobre otro para formar sus costumbres, sus hábitos y su destino ${ }^{62}$. Y una industria tan peligrosa no podía dejarse a la aventura. Por ello tenía pleno sentido la existencia de una autorización previa. Lo que se hallaba en juego era un poder superior al de las Cámaras: la forja de los ciudadanos. Dejarla en manos de los enemigos de la sociedad nueva era poner las semilla del descontento y la revolución ${ }^{63}$. Desde el momento en que el menor salía de la casa paterna y entraba en la escuela, el Estado debía intervenir, pues se encontraba en el dominio público. Y esta intervención tenía tres condiciones: garantías previas, vigilancia y represión severa en el caso de la comisión de delitos ${ }^{64}$. Para Cousin se traba de un principio racional, cuya presencia era posible constatar a lo largo de la historia desde los tiempos antiguos. Cousin construía así una narrativa en la cual se veía al Estado, identificado con el rey, ganar en protagonismo frente a la Iglesia en la organización de la enseñanza, desde Carlo Magno hasta la Revolución Francesa, pasando por Felipe el Hermoso y Enrique IV . Y en medio de esta historia no faltaba la referencia obligada a los jesuitas, acusados de todo tipo de vicios morales y sociales. La enseñanza de todos estos siglos, desde la Baja Edad Media, era que el Estado no había renunciado nunca a su poder de enseñar, ni entregado completamente este derecho a ningún particular o corporación ${ }^{65}$. Y tras la Revolución, Cousin se detenía en la gran obra de Napoleón: la construcción de la Universidad, el control total de la enseñanza por el Estado. Citaba a este respecto una frase de Leibniz suficientemente significativa de lo que estaba en juego con la libertad de enseñanza o su control por el Estado: "Donnezmoi l'instruction publique pendant un siècle, et je changerei le mon". Pero no se trataba de cambiar nada, sino de asentar sobre bases firmes la nueva sociedad surgida de la Revolución ${ }^{66}$. Napoleón había creado la Universidad como corporación del Estado. La autorización previa, introducida por una ley de 1802, pasaba ahora a la Universidad, que -en palabras de Cousin- no era otra cosa que "el gobierno aplicado a la instrucción pública"67.

Pasaba Cousin a continuación a defender el plan de estudios de la instrucción secundaria, deteniéndose en la materia que más críticas había recibido: la filosofia. Para Cousin no se podia prescindir de la filosofia, pero su enseñanza debía ser respetuosa con todas las confesiones religiosas y particularmente con la mayoritaria, esto es la católica, pero sin convertirse en

\footnotetext{
62 Victor Cousin, Oeuvres. Instruction publique, II, Pagnerre Ed., París, 1850, pp. 15-17.

63 Ídem, pp. 18-19.

64 Ídem, p. 21.

65 Ídem, pp. 21-40.

66 Ídem, p. 44.

67 Ídem, p. 50.
} 
instrumento de ninguna68. Asumía así los postulados del eclecticismo, que por esos años informaba, efectivamente, la enseñanza de la filosofia en la Universidad. En este sentido, rechazaba Cousin que la filosofia que se enseñase se correspondiese solo con las verdades de la religión católica, pues debía ser universal y servir a los seguidores de los diferentes credos. En este sentido, se mostraba contrario a la división de la enseñanza por confesiones religiosas ${ }^{69}$.

Cousin terminaba su intervención criticando el trato privilegiado que la ley otorgaba a los seminarios menores y uniendo la causa de la Universidad a la de la preservación de los principios de la Revolución Francesa ${ }^{70}$. La Revolución se presentaba así como elemento legitimador de todo su discurso, a través de la identificación de su postura con la nueva sociedad surgida de este gran acontecimiento fundante de la Francia moderna. Lógicamente, la operación de apropiación de la legitimidad constitucional por Cousin no era algo exclusivo suyo, ni mucho menos original. De un modo u otro, la conexión de los argumentos políticos con los principios defendidos por la Revolución, especialmente en su primera fase, constituía un lugar común en el discurso liberal.

El discurso de Cousin fue contestando, entre otros, por Montalembert en la sesión del 26 de abril ${ }^{71}$. Para éste el proyecto de ley era contrario tanto a la libertad como a la religión deviniendo imposible la reconciliación por muchos deseada de la Iglesia y el Estado. La ley imponía tantas trabas a la creación y dirección de colegios particulares que confiscaba la libertad de enseñanza. Como después argumentaría Tocqueville, se trataba de una ley preventiva y restrictiva incompatible con la libertad. Montalembert no reclamaba el monopolio de la enseñanza para la Iglesia. Es más, entendia que desde el momento en que la Constitución negaba al catolicismo la condición de religión de Estado, esto ya no era posible. Por otra parte, dado que una parte de la sociedad ya no compartía las verdades católicas era justo que existieran centros de enseñanza no católicos ${ }^{72}$. Montalembert simplemente protestaba contra la intervención directa y exclusiva del Estado en la educación, que no solo entendía contraria a los derechos de la conciencia sino a la misma libertad política "base de nuestra constitución y condición de nuestra fe social". En este sentido, acusaba a los partidarios de la ley de convertir una libertad en una mera concesión del poder, en un privilegio que había que justificar, cuando el principio verdadero era más bien el contrario, esto es, que lo que debía motivarse era la restricción a la libertad ${ }^{73}$.

Tampoco la narrativa histórica defendida por Cousin era compartida por el conde de Montalembert. Nunca en la historia de Francia se había puesto en entredicho la libertad de enseñar de la Iglesia, ni el Estado había monopolizado la

\footnotetext{
68 Ídem, p. 66.

69 Ídem, p. 72.

70 Ídem, pp. 86-93.

71 Discours du Comte de Montalembert pair de France dans la discussion générale du projet de loi contre la liberté d'enseignement, séance de la Chambre des Pairs du 26 Avril 1844, extrait du Moniteur Universel, Imprimerie de Vrayet de Surcy et Cie, París, 1844
}

72 Ídem, p. 7.

73 Ídem, pp. 1, 6. 
enseñanza. Como resumía en una frase redonda "las antiguas universidades eran católicas y no eran exclusivas; la vuestra es exclusiva y no es católica". En este sentido, Montalembert acusaba a la enseñanza universitaria de fundir todas las religiones y destruir todos los símbolos. Aunque no lo citara expresamente, Montalembert se estaba aquí refiriendo claramente a las doctrinas eclécticas de Cousin ${ }^{74}$. En la narrativa construida por Montalembert, las pretensiones de control del Estado defendidas por la ley conectaban directamente con gobernantes mitológicos o reales de la antigüedad pagana, como Minos y Licurgo, o de la época del Terror, como Robespierre. Por el contrario, la legislación o los proyectos de ley tanto de la Asamblea Constituyente como del consulado y del directorio consagraban la libertad de educación. También aquí la Revolución actuaba como elemento legitimador del discurso, esta vez del católico. Y continuaba Montalembert citando autoridades y leyes que la favorecían. En este sentido tenía particular importancia la referencia a Constant, "que no era ni católico, ni jesuita"75.

Junto al argumento histórico, Montalembert acudía al argumento comparado: países como Bélgica, Inglaterra y sobre todo Estados Unidos demostraban la conciliación de la libertad y la religión, como había expuesto Tocqueville, a quien expresamente citaba, en su estudio sobre la democracia americana. Sin embargo, el sistema previsto por la ley, con autorización previa y supervisión posterior por parte del Estado se encontraba próximo al sistema despótico ruso ${ }^{76}$. Y a todo esto se añadía la sustitución de la fe por el escepticismo en la mayor parte de los estudiantes que pasaban por la Universidad 77 . Y si por mantener la fe, dejaban de acudir a la Universidad, entonces perdian la posibilidad de acceder mediante los estudios pertinentes a las funciones públicas ${ }^{78}$.

Montalembert terminaba su discurso aclarando que reclamaba la libertad, no solo para la Iglesia, sino para todos. No pretendía privilegios, sino la aplicación del derecho común. Con esto bastaba para que la Iglesia mantuviese su influencia sobre la parte de la población que todavía tenía fe. Esta argumentación debía salvar un último obstáculo: los privilegios acordados a los seminarios menores. Para Montalembert se trataba de excepciones justificadas por las cargas también impuestas: limitación del número de estudiantes y la prohibición de algunas órdenes religiosas que afectaba especialmente a estos centros. En cualquier caso, se mostraba favorable a aplicarles el derecho común siempre que este implicase la libertad de enseñanza: es decir, se mostraba partidario de aplicar la igualdad en la libertad, no en la servidumbre. Y de esta manera, siguiendo un argumento desarrollado también por Tocqueville en la Democracia en América, aunque no exclusivo suyo, el cristianismo podría contener la deriva materialista de la sociedad moderna ${ }^{79}$.

\footnotetext{
74 Ídem, p. 4

75 Ídem, pp. 6-8.

76 Ídem, p. 9.

77 Ídem, p. 10.

78 Ídem, p. 13.

79 Ídem, pp. 13-15. Vid. De la démocratie en Amérique, op. cit., tomo II, segunda parte, cap. XV.
} 
Frente a quienes acusaban al clero y a los católicos de reclamar la libertad de enseñanza como medio para hacerse con el control de la educación francesa, o actuar movidos únicamente por intereses estratégicos, Montalembert, argumentando en el marco del catolicismo liberal de su tiempo, ciertamente minoritario, habia tratado de demostrar que la libertad que se reclamaba era para todos, católicos y no católicos. Su discurso trataba de desmontar los argumentos de quienes veían una oposición insalvable entre la Iglesia y la sociedad nueva, como entonces se decía. Únicamente el régimen privilegiado de los seminarios menores resultaba difícil de reconciliar con su reclamación de la aplicación del derecho común a todos. Pero en este caso, el problema -según Montalembert- se resolvería implantando con todas sus consecuencias la libertad de enseñanza, también en los seminarios menores. De esta manera, todos podrían ser iguales, pero -como gráficamente había reclamado- en un régimen de libertad, no de servidumbre.

La tramitación del proyecto de ley en la Cámara de los Pares se saldó con la aprobación en el mes de mayo de una serie de enmiendas favorables a la posición del partido católico. Así, se acordó que, para restringir la enseñanza de la filosofia, el programa de estudios sería modificado por el Consejo de Estado, no por el Consejo Real de la Instrucción. Además, se redujo el número de profesores de la Universidad en el jurado encargado de conceder el diploma de capacidad. Se sustrajo también al Consejo Real y a los consejos académicos la jurisdicción sobre los centros de enseñanza particulares y se decidió, por último, que no podría haber persecución penal por enseñanzas sediciosas, sino solo por las inmorales ${ }^{80}$.

Sin embargo, el proyecto de ley con las enmiendas aprobadas en la Cámara de los Pares fracasaría en la Cámara baja. Allí se formó una comisión presidida por Thiers, de la que Tocqueville formó parte, para informar sobre la ley. No se han conservado las actas de dicha comisión, de manera que solo tenemos noticia de las ideas defendidas por Tocqueville a raíz de la presentación de su candidatura para formar parte de la Comisión, de la que dio noticia el Constitutionnel de 18 de junio de 1844. Su postura, a medio camino entre la defensa de la Universidad y la amplia libertad de enseñanza requerida por el partido católico, quedaba resumida en los siguientes principios:

\begin{abstract}
"Una libertad sincera, limitada por serias garantías; el mantenimiento y consolidación de las escuelas del Estado; la facultad real concedida a las escuelas libres para entrar en una competencia leal con la Universidad. Cada ciudadano debe poder hacer que se eduque su hijo según le parezca mejor. Es de aquí de dónde resulta preciso partir: éste es el derecho" 81.
\end{abstract}

Se puede afirmar, por tanto, que la postura de Tocqueville era claramente favorable a la libertad de enseñanza entendida como el derecho de los padres a que su hijo fuera educado en los principios que ellos entendiesen más apropiados. Con la misma finalidad de favorecer esta libertad se mostraba contrario al certificado de estudios, previsto en el art. 3 del proyecto, acreditativo de haber cursado dos años en un establecimiento de pleno ejercicio. Para Tocqueville cualquier estudiante debía poder presentarse el examen de

80 A. Debidour, Histoire des rapports, op. cit., p. 461.

81 OC, III-2, p. 510. 
bachillerato con independencia del centro donde hubiera cursados sus estudios. Sin embargo, no se trataba de una libertad sin limites. Tocqueville reconocía al Estado el poder de garantizar un uso razonable de la libertad mediante el establecimiento de garantias precisas. Lo que no se podía defender era la limitación de esta libertad de enseñanza por miedo a que los católicos abusasen de ella. Entre las garantías exigibles a los centros docentes, Tocqueville incluía el cumplimiento de determinadas condiciones de moralidad, de ciencia y de actitud, aunque no especificaba cuáles. También reconocia al Estado el derecho de excluir de la enseñanza a determinadas personas cuyos antecedentes no ofreciesen suficientes garantias o a asociaciones politicas o religiosas no reconocidas por él ${ }^{82}$. En definitiva, se puede afirmar, que Tocqueville reconocía una amplia capacidad de regulación de la enseñanza al Estado, diferenciándose así de las posiciones más extremas defendidas por el partido católico.

Por otra parte, Tocqueville se mostraba contrario a la elevada presencia de la Universidad en los jurados encargados de conceder los títulos de capacidad. El principio de libre competencia le parecía incompatible con que fuera una de las partes en juego quien decidiera la idoneidad de las otras para enseñar. Debia corresponder al Estado a través de una institución neutral, como eran los tribunales ordinarios. Por último, en esta línea de evitar cualquier situación de privilegio juzgaba que los seminarios menores debian someterse al derecho común 83 .

Una vez más, Tocqueville elegía el partido de la moderación, con el riesgo de no ser aceptado ni por aquellos católicos que defendian una libertad de enseñanza concebida en términos más amplios, ni por aquellos que, por temor a la influencia del clero en la formación de las jóvenes generaciones, eran partidarios del férreo control de la enseñanza secundaria por la Universidad. Aún así, puede decirse que en este asunto la posición de Tocqueville mostraba más coincidencias con la defendida por Montalembert y el partido católico que con la auspiciada por Cousin. No podía ser de otra manera, pues en este asunto la causa de la libertad era defendida principalmente por los católicos. Sin embargo, cabría también apuntar que el término medio defendido por Tocqueville concedía un gran protagonismo al Estado en la ordenación de la enseñanza secundaria; un papel estatal que efectivamente actuaba como límite de la libertad de enseñanza. En este sentido, Tocqueville no dudaba en afirmar en una carta a Louis Bouchitté, de 4 de febrero de 1844, que la educación laica era la garantía de la libertad de pensar, de manera que la Universidad debía seguir siendo el lugar principal de los estudios. Además, el Estado debía conservar unos derechos amplios de supervisión sobre las escuelas, incluidas aquellas que no le pertenecian ${ }^{84}$.

El informe de la comisión de la Cámara de Diputados encargado de revisar el proyecto de ley con sus enmiendas fue encomendado a su presidente Thiers ${ }^{85}$. Su postura reviste particular interés, pues representa junto a la de otros autores

\footnotetext{
82 Ibídem.

83 Ídem, p. 511.

${ }^{84}$ A. de Tocqueville, Lettres Choisies, op. cit., p. 546.

${ }^{85}$ Rapport de $M$. Thiers sur la loi d'instruction secondaire fait au nom de la comission de la Chambre de Députés dans la séance du 13 juillet 1844, Paulin Editeur, París, 1844.
} 
como Cousin, la defensa de las tesis adoptadas por los liberales favorables a un estrecho control de la enseñanza secundaria por parte de la Universidad. Como ha señalado Battista, el problema al que se enfrentaban estos liberales era hacer compatible su pretendido liberalismo con su defensa de la intervención directa del Estado en materia educativa, limitativa de las libertades de los ciudadanos en este ámbito. Thiers distinguía el derecho de educar del resto de derechos de los particulares, como la libertad de empresa. La libertad de enseñanza se fundaba sobre el derecho del padre de familia. De esta manera -proseguía Thiers- el niño pertenece al padre, que ve en él su posteridad, y al Estado, que ve en él al ciudadano futuro, al continuador de la nación, a quien debe formar en el amor a la Constitución, a las leyes y a su patria. Estas dos pertenencias engendran dos derechos: uno del padre y otro del Estado. La verdad radica en conciliar estos dos derechos $^{86}$. Un régimen de libertad de enseñanza, según Thiers, es aquel con una variedad de sistemas que permiten atender las preferencias de los padres, pero que tienen en común ser conformes al genio de la nación ${ }^{87}$. Thiers concretaba en sentido negativo esta enseñanza común a todos, exigible por el Estado. No se podía tolerar que los menores fueran educados como ciudadanos de otro país o de otro tiempo, creyendo que la Revolución Francesa había sido un crimen, Napoleón un usurpador o la revocación del Edicto de Nantes una decisión admirable 88 . De esta manera, Thiers pretendia justificar a partir de los contenidos mismos de la enseñanza, la intervención tanto previa como posterior del Estado sobre los colegios particulares. De nuevo quedaba claro el hondo calado del problema que se hallaba en juego: la educación de la juventud y con ello el futuro político de la nación. No era, pues, solo un problema de libertades; se trataba también de la lucha por el relato histórico de la Francia moderna y con ello de la configuración de la nueva sociedad surgida del evento revolucionario. Thiers, como Cousin, Montalembert y todos los que intervinieron en este apasionado debate, eran conscientes de que el destino de la sociedad francesa radicaba en la educación. Napoleón lo había entendido perfectamente: el monopolio de la educación por parte del Estado había sido su respuesta. Los tiempos, sin embargo, habían cambiado y con la ampliación de las libertades constitucionales el modelo debía ser reformado.

En apoyo de su postura, Thiers construía una narrativa de la historia de la educación desde los siglos medievales hasta la Revolución. Napoleón había reorganizado todo el sistema universitario de manera que reflejara la unidad de la nación, como había sucedido con la Justicia o con la Administración pública y había fundado la Universidad como corporación de profesores laicos, imbuidos del espíritu del siglo, esto es, de la Revolución ${ }^{89}$. A continuación, el informe de la comisión analizaba los puntos claves de la ley: la exigencia de autorización previa, los requisitos y garantías para abrir establecimientos escolares, la jurisdicción en el ámbito escolar, el contenido de los programas y, por último, la excepción del régimen general concedido a los seminarios menores ${ }^{90}$.

\footnotetext{
86 Ídem, 9.

87 Ídem, 11.

88 Ídem, 13.

89 Ídem, 13-19.

90 Ídem, pp. 27 ss.
} 
El informe Thiers se movió en la dirección opuesta a las enmiendas aprobadas por la Cámara de los Pares y estableció un régimen más estricto para el clero: mantuvo los requisitos de moralidad, grados y capacidad para la apertura de los centros, junto a la declaración de no pertenecer a ninguna congregación no reconocida; devolvió la jurisdicción al Consejo Real y a los consejos académicos, con la obligación de vigilar e inspeccionar todos los establecimientos; encomendó también al Consejo Real la redacción de los programas escolares y sometió a los seminarios menores al régimen anterior, es decir, al existente en la ordenanza de $1828^{91}$.

El informe de Thiers fue finalmente aprobado por la Cámara de Diputados. Fue un golpe decisivo a la ley, aunque oficialmente el motivo aducido para dejar morir el proyecto fue la dimisión de Villemain por motivos de salud. A pesar de ello, Tocqueville decidió proseguir la lucha por la libertad de enseñanza a través del periódico Le Commerce, de cuyo comité de redacción formaba parte. Se trataba de un periódico de oposición al gobierno que reclamaba la aplicación integra de la Constitución de $1830^{92}$. Su director era un liberal de izquierdas, Charles-Arnold Scheffer ${ }^{93}$. En una carta a Corcelle, también comprometido en el periódico, Tocqueville le recordaba que su objetivo había sido crear en la prensa opuesta al gobierno un periódico totalmente independiente de Thiers que pudiera luchar contra él en los principales asuntos de política interior e internacional y que, además, defendiera "desde el punto de vista liberal la libertad de enseñanza" sin mezclarse en la guerra que otros periódicos habian declarado al clero ${ }^{94}$.

\section{LA DEFENSA DE LA LIBERTAD DE ENSEÑANZA EN LE COMMERCE}

El primer artículo de Tocqueville en Le Commerce sobre la libertad de enseñanza es de 29 de julio de 1844. A éste le siguieron otros. El último es de 8 de julio de 1845. Algunos de ellos quedaron inéditos por la oposición a su publicación de su amigo Corcelle, también editor del periódico ${ }^{95}$. El hilo conductor de todos ellos era la libertad de educación y la libertad religiosa, dos libertades que en la mente de Tocqueville aparecian inextricablemente unidas. Refiriéndose a la primera de ellas escribia:

\footnotetext{
“¿De qué se trata en efecto? ¿Del ejercicio de algunos derechos secundarios? No, se trata de una de las primeras libertades de las que los hombres en sociedad pueden reclamar su uso, de una libertad tan sagrada como la libertad religiosa con la cual se confunde y que siguiendo la bella expresión de M. de Lamartine restituye a la familia la propiedad sobre ella misma"96.
}

91 A. Debidour, Histoire des rapports, op. cit., p. 462.

92 Vid. Robert Boesche, Tocqueville and Le Commerce: A Newspaper Expressing his Unusual Liberalism, Journal of the History of Ideas, $\mathrm{n}^{\circ}$ 44-2, 1983, pp. 277-292.

93 Ana Maria Battista, Lo spirito liberale, op. cit., p. 94.

94 Tocqueville a Corcelle, 13 de agosto de 1844, OC, XV-1, p. 183.

95 En una carta de 23 de agosto de 1844 se quejaba a Corcelle de no haber permitido la publicación de algunos artículos suyos. Aunque respetaba la opinión de su amigo le echaba en cara que no pronunciarse en esos momentos sobre la cuestión de la libertad de enseñanza, que era el asunto que más preocupaba al público, no era solución al problema. OC, XV-1, p. 189.

96 Artículos sobre la libertad de enseñanza no incluidos en Le Commerce (1844), OC, III-2, p. 548. 
Como se deduce de lo dicho hasta ahora, la polémica sobre la libertad de enseñanza aparecía unida a otros temas especialmente relevantes en el pensamiento de nuestro autor, como la limitación que el ejercicio de algunos derechos presentaba a la potestad del Estado o, muy especialmente, el papel de la Iglesia en el ámbito educativo, esto es, en la formación de los ciudadanos de la nación francesa. Sin embargo, lo que a Tocqueville preocupaba particularmente de la polémica sobre la libertad de enseñanza era precisamente la polémica. Aun cuando su visión, como hemos visto, era favorable en términos generales a la libertad y, por tanto, conectaba más con la postura católica, no dejaba de acusar al clero o, al menos, a una parte de él, de haber convertido a la Iglesia en un partido político más y haberla enfrentado con el Estado. Se refería Tocqueville en particular a los ataques que, como vimos, algunos eclesiásticos habian lanzado a la Universidad en cuanto tal, y en particular a su enseñanza. En este sentido, desde su primer artículo, Tocqueville trataba de desmarcarse de aquellos que -en su opinión- reclamaban la libertad de enseñanza pero siguiendo motivaciones que nada tenían que ver con la libertad. La libertad de enseñanza que Tocqueville reclamaba encontraba su anclaje más profundo en el respeto a la "libertad misma del espíritu humano, al respeto debido a su conciencia"97. Se trataba de una consecuencia necesaria de las nuevas instituciones, esto es, de las implantadas en la Francia postrevolucionaria. Al mismo tiempo mostraba la sinrazón de aquellos que se oponian a esta libertad aduciendo que los legitimistas la reclamaban. Lo mismo sucedía con otras libertades, como la de prensa. Lo grande de estas libertades era que no protegían solo a los liberales, como él mismo, sino a todos los que sufrian opresión. Tocqueville terminaba este primer artículo criticando algunos aspectos de la ley propuesta: la supresión de la libertad de métodos obligando a todos los estudiantes a aprender lo mismo y de la misma manera; o que las condiciones para abrir establecimientos fueran demasiado difíciles, complicadas y arbitrarias ${ }^{98}$. En la realidad era prácticamente imposible cumplirlas. De esta manera Tocqueville adelantaba ya, en consonancia con lo defendido meses antes en la Cámara, los temas centrales sobre los que construiria en los meses siguientes su defensa de la libertad de enseñanza.

En el conflicto escolar no estaba solo en juego la protección de la libertad de enseñanza consagrada en la Constitución, sino sobre todo la preservación de la religión. Como había expuesto ya extensamente en la Democracia en América ninguna sociedad libre y más aún si era democrática, podía sobrevivir sin la religión ${ }^{99}$. Y los ataques a la Universidad por parte de algunos eclesiásticos le parecía que habian hecho renacer de sus cenizas los conflictos que en el siglo XVIII había visto enfrentarse a la filosofia con el catolicismo y más tarde a la Revolución con la Iglesia. El clero -afirmaba en un artículo que finalmente no fue publicado- que había salido de la vida pública en 1830 volvía ahora a entrar como un partido propio:

97 OC, III-2, p. 512.

98 Ídem, pp. 512-515.

99 Vid. A. de Tocqueville, De la démocratie en Amérique, op. cit., tomo II, parte I, cap. V. pp. 3334: "Pour moi, je doute que l'homme puisse jamais supporter à la fois une complète indépendence religieuse et une entière liberté politique; et je suis porté à penser que, s'il n'a pas de foi, il faut qu'il serve, et, s'il est libre, qu'il croie”. 
"Los amargos recuerdos de la lucha que la sociedad nueva había en otro tiempo sostenido contra la Iglesia se han despertado, los muertos del siglo XVIII se han levantado de sus tumbas, a la reacción religiosa ha seguido una reacción contraria; la cuestión ha caído en el dominio de la política, de cuestión de principio se ha convertido en cuestión de partido" 100 .

Según Tocqueville, el clero no se conformaba con reclamar la parte que, conforme al derecho común, le correspondía en la educación de la juventud, sino que pretendian ser los únicos capaces para llevar a cabo esta tarea. Esta opinión la fundamentaba en los ataques ya referidos a la Universidad y a algunos de sus profesores, con el consiguiente enfrentamiento entre los partidarios de la Universidad y los de la Iglesia o, al menos, un sector de ella ${ }^{101}$. No parece que Tocqueville se refiriera a una pretensión por parte de la Iglesia de monopolizar la enseñanza de la juventud, pretensión absolutamente utópica en aquellos años. La postura de Montalembert, aun cuando fuera representativa solo del sector más liberal del catolicismo, era clara al respecto. Tocqueville parece más bien referirse a los presupuestos que la descalificación de la enseñanza de la Universidad, por considerarla incompatible con la fe católica, parecian sugerir, esto es, que solo los clérigos podian aportar una enseñanza moral de calidad.

El problema de este enfrentamiento era el efecto pernicioso en las creencias religiosas de los franceses: ¿cómo iba a vivir nuestra sociedad -se preguntaba Tocqueville- sin creencias? Solo la religión era capaz de elevar las miradas por encima de este mundo a realidades más grandes que el propio hombre. Además, la religión era capaz de producir una influencia regular sobre las costumbres privadas e indirectamente sobre los demás asuntos: ¿Cómo podía existir una vida pública ordenada si la vida privada se hallaba desordenada o con problemas? De aquí, añadia Tocqueville insistiendo en una verdad clave en su sistema de pensamiento, que todos los pueblos libres reconocieran que estaban más necesitados que los demás de las creencias ${ }^{102}$. En unas notas tomadas para preparar un artículo destinado a Le Commerce, Tocqueville situaba en la unión de la libertad y la religión una de las principales fuentes de paz para el futuro. En nota a pie de página recalcaba su deseo de que el espíritu de "nuestra Revolución” y el espíritu de la Iglesia se aproximasen ${ }^{103}$.

En otras notas redactadas en octubre de 1844, para preparar un discurso en la Cámara que finalmente no pronunció, Tocqueville volvía sobre la misma idea. El texto es especialmente interesante porque refleja con particular claridad el papel que en su opinión la religión y, con ella, la Iglesia estaba llamada a desempeñar en la sociedad liberal. La idea fundamental de su intervención era el reacomodamiento de la religión y la libertad, pues para Tocqueville la sociedad nueva no podía funcionar si se las separaba. El argumento para sostener esta

100 "Les amers souvenirs de la lutte que la societé nouvelle avait jadis soutenue contre l’Église se sont réviellés, les morts du XVIIIe siècle se sont levés de leurs tombeaux, à la reaction religieuse a succédé une réaction contraire; la question est tombée dans le domaine de la politique, de question de principe elle est devenue question de parti”. Morceau que Corcelle $m$ 'a empêché d'insérer dans Le Commerce en 1844, OC, III-2, p. 548. Según el editor, André Jardin, estos escritos son de mediados de agosto de 1844.

101 Ídem, p. 547.

102 Ídem, p. 519.

103 Ébauche d'article sans doute destiné au Commerce, OC, III-2, p. 523. 
afirmación estaba íntimamente relacionado con la distinción de los órdenes religioso y político a los que dedicó páginas especialmente sugerentes en la Democracia en América. El primero, inmutable y no sometido a los ataques de la razón ni a los vaivenes del tiempo, servía como anclaje del segundo donde la libertad de actuación era completa ${ }^{104}$. En esta ocasión, también relacionaba el mantenimiento de la religión con la preservación de "una autoridad en el mundo intelectual y moral", en una sociedad que veía desaparecer todo resto de autoridad en el orden social y en la familia. Usando un argumento ya utilizado en su magna obra, la pérdida de esta autoridad religiosa conduciría a los hombres a buscar otra en un gran poder politico con la pérdida consiguiente de la libertad política. Con expresión gráfica afirmaba que "si se abolen las creencias, serán necesarios los soldados y las prisiones". Una vez más la religión era presentada por Tocqueville como el principal baluarte de la libertad, del orden social, como la primera fuente de moralidad sin la cual la sociedad no podría subsistir ${ }^{105}$. La idea no era nueva ${ }^{106}$, ni siquiera original, aun cuando probablemente ningún otro autor la convirtiera como Tocqueville en el centro de su proyecto intelectual y político. Además, en este caso, Tocqueville lograba conectarla con el acontecimiento fundacional de la Francia moderna, esto es, con la Revolución Francesa. Junto a la religión, la libertad, una libertad que existía para todos, no para un solo partido, que incluía por tanto también a la Iglesia y a los católicos, y que se traducía en la existencia de un único derecho para todos, de un derecho común. La Revolución, que no dudaba en calificar de "gran monumento de nuestros padres", no podía traducirse en la sustitución de una tiranía por otra; en este caso, por la tiranía del Estado a través del mantenimiento del monopolio universitario ${ }^{107}$.

En efecto, el principio general que parece inspirar la postura de Tocqueville en lo relativo a la libertad de educación es similar al defendido en otros asuntos: la existencia de un derecho común a todos los ciudadanos. En este sentido Tocqueville no dejaba de criticar en un artículo de 24 de septiembre de 1844 el voto adoptado por el Consejo General de la Vendée prohibiendo al clero la enseñanza. Para Tocqueville, el espíritu tanto de la Revolución de 1789 como de la de 1830 exigia tratar al clero como al resto de los ciudadanos. En este sentido resultaba legitimo imponer al clero la posesión de determinados títulos y su sometimiento a la inspección del Estado ${ }^{108}$. Lo que no le parecía admisible era la existencia de monopolio alguno en materia de educación. Privar al clero de las facultades que le correspondian como ciudadanos -afirmaba Tocqueville- era

104 A. de Tocqueville, De la démocratie en Amérique, op. cit., tomo I, parte II, cap. IX, p. 227 y tomo II, parte I, cap. V, p. 33.

105 Idées de discours, octubre 1844, OC, III-2, p. 551.

106 Como señala Jennings, la mayor parte de los autores se oponían a la teoría de Bayle según la cual era posible construir una sociedad estable de ateos. La religión y en particular el cristianismo eran vistos como salvaguarda de la moralidad y del orden social. Jeremy Jennings, Revolution and the Republic: a history of political thought in France since the eighteenth century, Oxford University Press, Oxford, 2013, p. 305.

107 Ibidem.

108 Article sur un voeu du Conseil Général de la Vendée, Le Commerce, 24 septiembre 1844, en OC, III-2, pp. 524-525. 
implantar la tiranía en nombre de la libertad ${ }^{109}$. En este sentido, Tocqueville coincidia con Thiers en considerar la libertad de educación un derecho de los padres, pero difería sustancialmente en el alcance reconocido a este derecho y, por tanto, en su regulación. Como Thiers, Tocqueville pensaba que la educación debía ser conforme a las leyes del país, pero ello no impedía en modo alguno que también tuviese un contenido religioso. En concreto, para Tocqueville la libertad de educación implicaba, entre otras cosas, que cada ciudadano podía hacer educar a sus hijos por eclesiásticos, siempre que estos cumpliesen con las leyes requeridas con carácter general a los educadores. Por otra parte, y en clara consonancia con su elevado concepto de la religión en la formación del alma del ciudadano amante de la libertad, Tocqueville entendía que excluir a los clérigos de la enseñanza no solo era inconstitucional e ilegal, sino además contrario al interés público. Para Tocqueville no existía ningún país civilizado donde los clérigos de cualquier confesión religiosa no tomasen parte en la educación de la juventud. Y una prueba palpable de esta convivencia era la presencia de eclesiásticos en la Universidad 110.

La afirmación de un derecho común en esta materia implicaba también la exclusión de todo privilegio, ya fuera del clero, que no era el caso en aquella ocasión, ya fuera del Estado. En este punto, la postura de Tocqueville era bastante próxima a la defendida años antes por Benjamin Constant. Así se deduce no solo de la tesis defendidas por ambos, sino también de las referencias directas a Constant en las notas de Tocqueville. En concreto nuestro autor transcribe un fragmento de un texto de Constant tomado de una obra sobre la historia de la instrucción secundaria de Paul-Emile Gasc ${ }^{111}$. En él, Constant argumentaba que al dirigir la educación, el gobierno se arrogaba el derecho de imponer un cuerpo de doctrinas que aparecian asi dotadas de un cierto privilegio y de perseguir las opiniones contrarias. Para Constant, los padres tenian derecho a educar a sus hijos en centros escolares no dependientes del gobierno. La competencia del Estado en este ámbito era solo represiva, en caso de que se enseñasen opiniones contrarias a la moral. Su función era "velar y preservar, pero no entorpecer ni dirigir"112.

Cuatro meses después de la publicación de su primer artículo, Tocqueville retomó la pluma y publicó con fecha de 29 de noviembre el primero de una serie de artículos sobre el problema escolar que terminaría el 11 de diciembre ${ }^{113}$. En

109 Îdem, p. 525.

110 Îdem, pp. 525-526.

111 Aunque no cita el título de la obra, debió de tratarse de sus Etudes historiques et critiques sur l'instruction secondaire, considérée dans ses rapports avec l'état, l'université, le clergé et les familles, Suivies d'un projet de loi avec exposé des motifs, Adressé à Messieurs les Membres des Chambres législatives, Appert Ed., Paris, 1844.

112 OC, III-2, pp. 558-559.

113 La autoría Tocquevilliana de los artículos del 3, 5, 6, 8 y 11 de diciembre ha sido impugnada por Anna Maria Battista (Lo spirito liberale, op. cit., p. 104). Los argumentos dados por la profesora italiana se basan, por un lado, en cuestiones de estilo y, por otro, en la apelación de Tocqueville a los principios iusnaturalistas de 1789 como fundamento de sus posturas. Sin embargo, la presencia en estos artículos de citas y fragmentos procedentes de notas de trabajo de Tocqueville, así como la referencia a los principios de 1789 en estas notas, parecen dar la razón a André Jardin que los incluye en sus obras completas como salidos de la pluma de Tocqueville. Únicamente el artículo de 3 de diciembre nos plantea algunas dudas al referirse el autor a su 
ellos, Tocqueville retomaba algunas de las ideas ya pronunciadas en la Cámara o vertidas en los artículos publicados, así como en aquellos que no había podido publicar en Le Commerce. La cuestión religiosa y, por tanto, la correcta relación entre la Iglesia y el Estado aparecía como el tema de fondo de la regulación de la libertad de enseñanza. Por un lado, Tocqueville se quejaba de la focalización del discurso de la oposición en un tema en el que las coincidencias con el gobierno eran prácticamente totales y en el que, por tanto, no cabía oposición verdadera. En este sentido, Tocqueville estaba convencido de que la polémica sobre la cuestión religiosa solo beneficiaba al gobierno, pues mientras se discutía sobre estas cuestiones se dejaban de lado otras verdaderamente importantes, como el papel del Parlamento en la vida politica, la reforma de la ley electoral o la asistencia a las clases más desfavorecidas ${ }^{114}$. En definitiva, a Tocqueville le preocupaba la crisis de las instituciones politicas que salvaguardaban la libertad, como la soberanía nacional, el gobierno representativo, la extensión del individualismo, etc ${ }^{115}$.

Por otra parte, Tocqueville temía, como había ya manifestado en otras ocasiones, que la controversia sobre la escuela, convertida en polémica a favor o en contra del clero y de las congregaciones religiosas, se tradujese en un enfriamiento de la religiosidad en Francia, en un alejamiento de la Iglesia y la sociedad liberal, cuya tarea de reconciliación había motivado en parte su entrada en la vida política ${ }^{116}$. El problema, por tanto, no era como creían los periódicos de izquierdas que los jesuitas o la Iglesia se hiciese con el control del país. No era la libertad, sino la religión la que se encontraba en peligro'117. Era una idea que Tocqueville habia ya defendido con anterioridad en varias ocasiones, pero que ahora volvía a recalcar frente a las alarmas de los que veían en la proliferación de las órdenes religiosas y particularmente de los jesuitas una amenaza para el Estado y para las libertades consagradas por la Constitución. Para nuestro autor, la situación política de la Iglesia a partir de 1830 se diferenciaba claramente de la existente en el período anterior. Ya no existía como en la Restauración un gobierno "contrarrevolucionario y devoto" y, por tanto, el peligro de control del Estado por la Iglesia era irreal ${ }^{118}$. El problema era más bien el contrario.

lucha por la libertad de métodos y de educación durante la Restauración. Al mismo tiempo, la inclusión en este mismo artículo, como señala Jardin, de citas de Saint-Marc Girandin y de Lamartine utilizadas en artículos que quedaron inéditos (vid. OC, III-2, p. 533) y el tratamiento dado a algunos problemas, similar al existente en un borrador inédito de octubre de 1844, apuntan a la autoria de Tocqueville. OC, III-2, p. 569, nota 1. Es posible, sin embargo, que el artículo fuera solo parcialmente de Tocqueville.

114 "Loin que la querelle qui s'agite entre l'Université et le clergé, la philosophie et l'orthodoxie, la nation et les Jésuites, soit contraire au pouvoir qui dirige nos affaires, qui ne voit qu'elle le sert?”. Artículo de 29 de noviembre de 1844, Le Commerce, OC, III-2, pp. 563-564.

115 Artículo de 1 de diciembre de 1844, Le Commerce, OC, III-2, p. 567. Sin embargo, en una carta anterior, de 14 de septiembre, a su amigo Beaumont, Tocqueville había defendido que la querella entre la Universidad y el clero no afectaba realmente al país sino solo a los miembros de estos dos cuerpos. OC, VIII-1, p. 537. En una carta anterior a Corcelle, de 12 de octubre de 1833, se había expresado en el mismo sentido. OC, XV-1, p. 169.

116 Vid. artículo de 7 de diciembre de 1844, OC, III-2, p. 580.

117 Ibídem.

118 Artículo de 29 de noviembre de 1844, Le Commerce, OC, III-2, pp. 563-564. 
En su último artículo sobre la libertad de enseñanza, de 11 de diciembre, Tocqueville volvía sobre algunos de los argumentos expuestos en otras ocasiones. Se mostraba una vez más conforme con la regulación de este derecho, como se encontraban regulados otros derechos, como el de pensar, hablar o escribir. Pero regularlo no era destruirlo. En este sentido, parece claro que Tocqueville concebía este derecho como una exigencia de justicia previa a su regulación por el Estado. Por otra parte, manifestaba su oposición a todo monopolio, ya fuera de la Iglesia o, en este caso, del Estado y fundamentaba sus afirmaciones acudiendo a la historia. Una vez más la Revolución de 1789 constituía el punto de referencia obligado para toda toma de postura en el debate político. En este caso, Tocqueville diferenciaba tres momentos revolucionarios: uno liberal, con la Asamblea constituyente, otro centralizador, con la Convención y otro combativo con el Imperio. Su postura se identificaba con el primero de estos momentos, el más liberal de los tres. Al mismo tiempo, manifestaba su oposición a la política de la convención contraria a la libertad de enseñanza; una oposición que parecía partir del presupuesto de que los menores eran propiedad del Estado ${ }^{119}$. Tocqueville hacía así propia la narrativa liberal de su tiempo que trataba de conectar la construcción de las libertades en el siglo XIX con el momento fundacional de la Francia moderna, esto es, con la primera fase de la Revolución francesa, aquella anterior a los excesos de la Convención o a la pérdida de las libertades del Directorio primero y del régimen napoleónico después ${ }^{120}$. No era obstáculo para la consagración de esta narrativa que las medidas más radicales contra la Iglesia se hubiesen aprobado precisamente en estos primeros compases revolucionarios, ni que la Constitución Civil del Clero que supuso en la práctica la absorción de la Iglesia por el Estado y la división de la población en dos sectores irreconciliables se hubiese aprobado antes de la Convención. Más que los hechos en sí mismos, interesaba en esta narrativa la fuerza de los símbolos y el primer período constituyente de la Revolución venía asociado en la mente de los liberales decimonónicos a la aprobación de la Declaración de derechos del hombre y del ciudadano de 1789 y a la instauración de un régimen de libertades en el marco de una monarquía renovada. En una carta a su amigo Corcelle de noviembre de 1845 Tocqueville explicaba que habia hecho todo lo posible por crear en Francia un periódico [Le Commerce] que representase el verdadero espíritu de la Revolución Francesa, aunque había fracasado. Además -añadía Tocqueville- su decisión de abrazar "la causa y las ideas de 1789" le había llevado a romper con una parte de su familia. Quedaba asi de manifiesto que para nuestro autor la Revolución Francesa se identificaba con $1789{ }^{121}$.

119 OC, III-2, pp. 584-585. En un artículo en Le Commerce de 3 de mayo de 1845, Tocqueville realizaba una presentación de la legislación revolucionaria sobre libertad religiosa paralela a la ofrecida aquí con motivo de la educación. Distinguía así la primera época, de la Asamblea Constituyente, que había respetado la libertad religiosa, de las otras dos, de la República y el Imperio, que habian prohibido las asociaciones religiosas o las habían sometido a autorización previa. OC, III-2, p. 610.

120 Ceri Crossley, French Historians and Romanticism. Thierry, Guizot, the Saint-Simonians, Quinet, Michelet, London-New York, 1993, p. 4.

121 Tocqueville a Corcelle, 13 de noviembre de 1845, Oeuvres Complètes, Gallimard, Quarto, pp. 559-560, cit. en Jean-Louis Benoît, Tocqueville, op. cit., p. 249. 


\section{A MODO DE CONCLUSIÓN}

La inclusión en la Carta Constitucional de 1830 de un derecho relativo a la libertad de enseñanza planteó a lo largo del periodo orleanista el problema de su concreción jurídica. Frente al monopolio ejercido hasta ese momento por la Universidad según el modelo napoleónico de enseñanza, se hacía preciso ahora establecer un régimen de libertad. El problema sin embargo era complejo, pues la regulación de la libertad de enseñanza, con la superación del monopolio universitario, traía a primer plano el reto de definir el papel de la Iglesia en el nuevo orden liberal y de la religión en la formación de la juventud francesa.

Frente a las posturas ampliamente liberalizadoras de la enseñanza defendidas por los católicos liberales, paradigmáticamente representados por el conde de Montalembert, y las favorables a un férreo control universitario de la educación que dejaba poco espacio a la iniciativa privada y sobre todo eclesiástica en la educación, Tocqueville trató de convencer de la necesidad de adoptar un régimen claro de libertad de enseñanza secundaria que sin embargo reconocía amplias competencias de regulación e intervención al Estado. A este correspondía, como en otros derechos, el establecimiento de garantías precisas que asegurasen su correcto ejercicio. Entre otros extremos, el Estado -según Tocqueville- tenía derecho a exigir de los profesores y directores de los centros educativos determinadas condiciones de moralidad, de ciencia y de actitud, aunque no especificaba cuáles. Igualmente reconocía al Estado el derecho de excluir de este ámbito a aquellas personas que no ofreciesen suficientes garantías o a aquellas asociaciones no reconocidas por el Estado. Conviene recordar, en este sentido, que la legislación francesa en materia de congregaciones religiosas era sumamente restrictiva, aun cuando en la realidad bastantes congregaciones fueran de hecho toleradas por el Estado pese a no tener reconocimiento alguno. Más delicado aún era el caso de los jesuitas. La narrativa ilustrada-liberal de la que Tocqueville participaba los presentaba como una amenaza para el Estado y el orden social, incapacitándoles así para participar en la formación de la juventud.

De todo lo anterior, podemos concluir, que las limitaciones reconocidas por el derecho y también por Tocqueville a la libertad de enseñanza mediado el siglo XIX eran considerables. Sin embargo, el principio que inspiraba en cualquier caso su postura, en este como en otros temas, era el sometimiento del clero al derecho común, de manera que gozasen de las mismas libertades que el resto de ciudadanos. Además, entendía contraria a la libertad de enseñanza la inclusión de requisitos de capacidad y mérito tan gravosos que hiciesen prácticamente imposible su ejercicio por los particulares. Igualmente consideraba que la exigencia de una autorización previa como requisito para el ejercicio de la enseñanza constituía una violación clara de este derecho. En resumen se puede concluir que en este tema su postura se caracterizaba por la moderación, alejada tanto de las exigencias de libertad de enseñanza sin apenas mediación del aparato estatal, especialmente de la Universidad, como de las que desde las filas tanto doctrinarias como liberales de izquierdas postulaban un régimen próximo al monopolio de la educación secundaria por la Universidad. En este tema parece claro que la postura más liberal se encontraba en el bando católico mientras los liberales defendian unas tesis claramente limitadoras de los derechos consagrados en el texto constitucional. Entre unos y otros, pero más cerca de la posición de los católicos, Tocqueville trataba de encontrar una postura que 
lograse conciliar las exigencias de la libertad de educación, concebida como derecho, con las derivadas de la potestad de supervisión y control del Estado en una materia tan sensible para la construcción de la nueva sociedad francesa.

Lo que en cualquier caso parece que más preocupaba a Tocqueville no era tanto la regulación de este derecho, sino el clima anticlerical y anti-cristiano que las críticas a la Universidad por parte del clero estaba haciendo renacer en la sociedad francesa. Tras un periodo de relativa calma, durante los primeros años de la monarquía de julio, en que la separación de la Iglesia y del Estado se había traducido -según Tocqueville- en un claro renacimiento religioso en la sociedad francesa y entre los jóvenes, la polémica desatada por la tramitación de las diferentes leyes de educación secundaria estaba creando un clima social que amenazaba con enfriar espiritualmente la sociedad. Este efecto indeseado del problema escolar revestía para Tocqueville una especial gravedad, pues religión y libertad constituían dos realidades íntimamente ligadas en la mente de nuestro autor. Y el debate sobre la libertad de enseñanza en los periódicos hacía peligrar la conciliación del espíritu de religión con el de libertad, la reacomodación en definitiva de la Iglesia con el Estado en la nueva sociedad liberal, objetivo al que Tocqueville había consagrado sus mejores esfuerzos, tanto intelectuales como políticos.

Por último, resulta claro a partir de lo expuesto que en el debate sobre la libertad de educación la construcción de narrativas históricas en un sentido o en otro desempeñó un papel central. En el caso de Tocqueville, 1789 aparecía como momento simbólico, de consagración de nuevas libertades, al que resultaba necesario volver para orientar el futuro del país. A este momento fundacional, origen de la nueva sociedad liberal en parte construida y en parte todavía por construir, se oponían tanto el período republicano de la Convención, como el autoritario de Napoleón. Solo en el primero de estos períodos la regulación de la enseñanza había seguido principios liberales, que ahora, medio siglo después, resultaba preciso recuperar, de manera que Iglesia y Estado, religión y libertad, pudiesen coexistir en armonía.

Enviado el (Submission Date): 19/01/2018

Aceptado el (Acceptance Date): 14/03/2018 